\title{
Natureza da Ciência no ensino de ciências: uma proposta baseada em "temas" e "questões"+*1
}

\author{
André Ferrer P. Martins ${ }^{2}$ \\ Centro de Educação - UFRN \\ Natal - RN
}

\section{Resumo}

Este artigo aborda questões relativas ao saber sobre a ciência no ensino de ciências, em particular a questão "o que ensinar" no que diz respeito a conteúdos metacientíficos. Exploramos a existência de uma "visão consensual” (VC) sobre a Natureza da Ciência (NdC) na literatura de pesquisa da área de ensino de ciências, mostrando que há diferentes rotas, terminologias, pontos de partida e conclusões quando analisamos a literatura em torno desse "consenso". Em seguida, evidenciamos certas características - de forma e de conteúdo - da VC e apresentamos determinadas críticas já endereçadas a ela, particularmente aquelas relativas ao uso de conhecimento declarativo pela VC, como também relativas aos conteúdos de algumas dessas afirmações. Na seção final do trabalho, sugerimos o que consideramos ser uma abordagem mais aberta, plural e heterogênea para lidar com o saber sobre a ciência no currículo escolar de ciências. Essa abordagem, baseada em "temas" e "questões", em vez de "princípios", tenta superar algumas das críticas previamente discutidas.

Palavras-chave: Saber sobre a ciência; Natureza da ciência; Epistemologia; Currículo de ciências.

\footnotetext{
" Nature of Science in Science Education: a proposal based on "themes" and "questions"

* Recebido: janeiro de 2015.

Aceito: maio de 2015.

${ }^{1}$ Uma versão preliminar e bastante reduzida desse trabalho foi apresentada na conferência GIREP-MPTL de 2014 (MARTINS; RYDER 2015).

2 E-mail: andre.ferrer@pq.cnpq.br
} 


\begin{abstract}
This work addresses issues related to knowledge about Science in Science Education, particularly about the question "what to teach" in relation to metascientific content. We explore the existence of a "Consensus View" $(C V)$ about Nature of Science (NOS) in the literature on the area of Science Education, showing that there are different routes, terminologies, starting points and conclusions when we analyze the literature around this "consensus". We then explore certain characteristics of the $\mathrm{CV}$ - related to its form and its content - and present some criticisms already made of it, particularly those regarding the use of declarative knowledge associated with the CV, as well the content of some of the statements. In the final section, we suggest what we consider to be a more open, pluralistic and heterogeneous approach to deal with knowledge about science in the school science curriculum. This approach, based on 'themes' and questions instead of 'tenets', attempts to overcome some of the criticisms previously discussed.
\end{abstract}

Keywords: Knowledge about science; Nature of Science; Epistemology; Science curriculum.

\title{
I. Introdução
}

Não é de hoje que a comunidade de educadores em ciência reconhece a importância do saber sobre a ciência para o ensino de ciências. Esse tema tem uma longa história na área e permanece sendo um desafio a ser enfrentado. Para além dos conteúdos presentes em diversos níveis de ensino, uma compreensão mais profunda de como a ciência funciona, como o conhecimento científico é produzido, validado e comunicado, assim como a própria natureza desse conhecimento, no que se refere às suas particularidades epistemológicas, tem sido vista como algo a ser buscado e com valor para a educação científica. Trata-se de um conteúdo metacientífico.

Mas por que ensinar sobre a ciência é relevante? O que ensinar? Como ensinar? Tais questões são cruciais como guias para a estruturação de currículos e não deveriam ser tomadas isoladamente, mas de modo articulado:

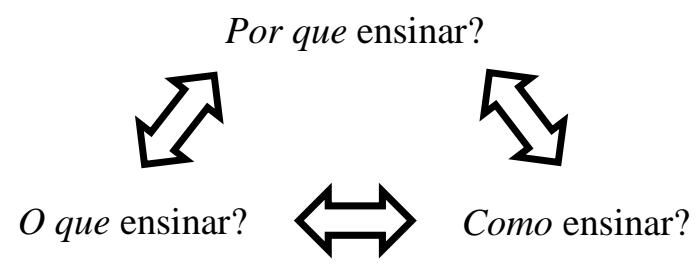


No entanto, o debate em torno das razões para o ensino de conteúdos metacientíficos tem sido de algum modo negligenciado nos últimos anos, em parte devido a um entendimento de que é algo relativamente "bem estabelecido". Em nossa visão, todo professor de ciências deveria, com frequência, questionar a si mesmo sobre tais razões. Uma visão clara a esse respeito contribuiria significativamente para dar sentido ao conhecimento escolar de ciências e à ideia de alfabetização científica. Embora reconheçamos que é essencial relacionar objetivos com conteúdos e estratégias, não é possível abordar essas três questões com a profundidade necessária em um único trabalho. Assim, o foco de nossa atenção será a segunda das questões apontadas.

O que ensinar? Uma maneira de atacar essa questão é de modo negativo, identificando "o que não deve ser ensinado". Ao longo das últimas décadas, diversos trabalhos na área evidenciaram a existência de um grande número de concepções equivocadas e ingênuas sobre a ciência, manifestas tanto por estudantes quanto por professores, tais como: concepção empíricoindutivista da ciência; visão rígida (algorítmica, exata, infalível) da metodologia científica; visão acumulativa e linear da História da Ciência; visão descontextualizada e socialmente neutra da atividade dos cientistas, visão individualista e elitista da ciência, entre outras (ver, p. ex.: GIL-PÉREZ et al., 2001; FERNÁNDEZ et al., 2002; LEDERMAN, 1992, 2007). O trabalho de Driver et al. (1996) já chamava a atenção para uma série de concepções problemáticas (p. ex.: cientistas trabalham isoladamente; o principal propósito da ciência é prover soluções para problemas técnicos; dificuldade em perceber o papel de entidades teóricas e modelos nas explicações científicas, entre outras).

Em seu conjunto, essas noções compõem, em grande parte, o que poderia ser caracterizado como uma concepção de senso comum da ciência e de seu desenvolvimento, amplamente presente em nosso cotidiano e propagada pelos veículos midiáticos (jornais, revistas, TV etc.), em geral, e até por livros didáticos e professores de ciências. De um ponto de vista mais filosófico, muitas dessas ideias se ajustam a um realismo "ingênuo", tal qual o denomina Bachelard (1991). Adjetivada dessa maneira ("ingênuo"), tal concepção sugere que o conhecimento pode ser apreendido pela experiência primeira e imediata, diretamente por meio da observação e da experiência. O realismo ingênuo - como um posicionamento epistemológico - pressupõe um realismo ontológico (no sentido da crença em mundo exterior pré-existente independente de nossa consciência) e assume que o conhecimento assim construído é uma cópia do mundo real objetivo. Bachelard, ao analisar os obstáculos epistemológicos à construção do conhecimento científico, afirma - de modo um tanto irônico - que o realismo é a única filosofia inata (BACHELARD, 1996, p. 163).

Conhecer concepções ingênuas e equivocadas do fazer científico representou avanço significativo das pesquisas na área e um entendimento daquilo que "não deve ser ensinado". Mas se pode atacar a questão de "o que ensinar?" por uma via positiva, ou seja, buscando construir um entendimento do que seria um conjunto de temas, aspectos, assuntos condizentes com a perspectiva de um ensino sobre as ciências. Esse caminho é potencialmente mais complexo e 
tem uma longa história. Particularmente, ao longo dos últimos anos, tem levado ao estabelecimento daquilo que se convencionou chamar de "visão consensual" sobre a Natureza da Ciência (NdC). A sigla NdC (NOS, em inglês), aliás, passou a predominar na literatura especializada a esse respeito.

Essencialmente, a chamada "visão consensual" (VC) estabelece um conjunto de aspectos, de caráter geral, a respeito dos quais haveria um consenso amplo no que diz respeito ao que se espera que esteja presente no currículo escolar de ciências. Como um referente para a instrução, a VC busca um consenso pragmático em torno de determinados aspectos que seria válido para se pensar a inserção da temática $\mathrm{NdC}$ nas escolas, portanto.

A VC tem recebido críticas de diversas naturezas (p. ex.: ALTERS, 1997; RUDOLPH, 2000; CLOUGH, 2007; ALLCHIN, 2011; IRZIK; NOLA, 2011; VAN DIJK, 2011; MATTHEWS, 2012; DUSHL; GRANDY, 2013), enquanto, por outro lado, vem sendo articulada e obtendo adeptos (p. ex.: LEDERMAN, 1992, 2007; McCOMAS et al., 1998a, 1998b; OSBORNE et al., 2003; McCOMAS, 2008; ABD-EL-KHALICK, 2012a, 2012b; LEDERMAN; BARTOS; LEDERMAN, 2014). Nesse ponto, cabe perguntar: é possível superar essas críticas e buscar outra forma de construir currículos e pensar sobre o que ensinar?

A literatura especializada da área mostra diferenças de rotas, pontos de partida, terminologias e conclusões, que revelam divergências que não devem ser desprezadas. Nas seções seguintes exploraremos brevemente certas características da VC - relacionadas à sua forma e ao seu conteúdo - e apresentaremos algumas críticas endereçadas a ela. Ao final, sugerimos uma abordagem alternativa a VC que busca superar boa parte das críticas.

\section{A "visão consensual": uma abordagem enfrentando críticas}

Em primeiro lugar, é importante afirmar que, para nós, está claro que um consenso em nível filosófico é inatingível. A ciência é um empreendimento social complexo demais para que dela se possa ter uma caracterização única. Diversos autores que se dedicaram a uma análise da ciência (p. ex.: Thomas Kuhn, Gaston Bachelard, Stephen Toulmin, Imre Lakatos, Larry Laudan, Karl Popper, Paul Feyerabend, dentre outros) trouxeram contribuições significativas a partir de perspectivas diversas. Essa riqueza de pontos de vista permite realçar diferentes aspectos da prática científica que contribuem para plasmar a visão pessoal de cada indivíduo acerca da ciência.

Consciente dessa falta de consenso em nível filosófico, a visão consensual também reconhece que todo conteúdo a ser ensinado deve passar necessariamente por um processo de transformação para se chegar a sala de aula, o que implica em simplificações, ajustes, omissões etc. (pode-se usar aqui a noção de "transposição didática" de Yves Chevallard (1985), ou a ideia de transformação do conhecimento por meio de uma sucessão de modelos (TABER, 2008)). O mesmo também ocorre com os conteúdos relativos à $\mathrm{NdC}$. Nesse sentido, a crítica endereçada a VC, de uma falta de consenso entre filósofos no que tange a uma caracterização da ciência (p. ex. em ALTERS, 1997), perde um pouco de sua força. 
Mas é a respeito de um segundo nível de consenso, válido para o ensino escolar de ciências, que iremos tratar aqui. Ele é a essência da própria ideia de "visão consensual". De certa maneira, a VC pode ser considerada um produto de uma espécie de "sabedoria partilhada" acerca da temática $\mathrm{NdC}$, reflexo de uma crítica (filosófica $e$ pedagógica) a uma visão de senso comum da ciência e de seu desenvolvimento. A uma tal "sabedoria partilhada" pode-se associar um conteúdo e uma forma que, embora imbricadas, podem ser separadas para fins de destaque e análise. Nosso objeto de atenção será, inicialmente, a particular forma que determinados trabalhos associados à VC assumem para representar essa "sabedoria partilhada" (a saber, o uso de conhecimento declarativo - ou "princípios", como ficará mais claro ao longo dessa seção). Veremos que a adoção dessa forma acaba por resultar em problemas com o conteúdo.

Quando observamos a literatura especializada a esse respeito, encontramos trabalhos que evidenciam a existência de diversos caminhos / rotas para se construir um entendimento em relação à pergunta "o que ensinar?" sobre $\mathrm{NdC}$, bem como a existência de diferentes terminologias, pontos de partida e conclusões.

Trabalhos centrais para o estabelecimento da VC, como os de McComas e Olson (1998), McComas et al. (1998b) e McComas (2008), p. ex., baseiam-se em um conjunto de documentos oficiais de educação científica, cuja análise leva à construção de "princípios" da $\mathrm{NdC}$ (os chamados "tenets", em inglês ${ }^{3}$ ). Esse caminho pode ser considerado mais normativo (ou nomotético) e acadêmico, o que pode ser ilustrado, inclusive, pelas próprias categorias usadas na classificação das ideias presentes nesses documentos (Filosofia da ciência, História da ciência, Psicologia da ciência e Sociologia da ciência), às quais representam áreas de conhecimento acadêmico relacionadas de algum modo à temática $\mathrm{NdC}$.

Outros trabalhos, como os de Driver et al. (1996) e Ryder (2001, 2002), p. ex., tomam um caminho diferente. No primeiro caso, chega-se a uma descrição de “o que ensinar?" a partir de um estudo empírico com estudantes entre nove e dezesseis anos de idade. Os dois últimos trabalhos partem da análise de trinta e um estudos de caso relacionados a situações envolvendo a interação de pessoas com a ciência fora de um contexto de ensino formal. Esse caminho pode ser considerado mais empírico e, num certo sentido, mais ideográfico (para usar a própria distinção feita por Driver et al., 1996, p. 58).

Como consequência, há diferenças nas conclusões. Embora haja uma grande similaridade entre aspectos da $\mathrm{NdC}$ levantados em todos esses estudos, também há diferenças significativas. As listas de princípios de NdC (Nature of Science tenets) contêm afirmações curtas, diretas e de caráter geral sobre a ciência, equilibrando, num certo sentido, conteúdos das quatro áreas (Filosofia da ciência, História da ciência, Psicologia da ciência e Sociologia da ciência). Já em Driver et al. (1996, p. 144-147) encontramos outra classificação ("base epistemológica para afirmações do conhecimento científico" e "ciência como empreendimento social"), cujas

\footnotetext{
3 Usaremos ao longo deste trabalho, indiscriminadamente, as duas expressões ("princípios" e "tenets"), uma vez que o termo em inglês é bastante conhecido na área e torna a identificação mais imediata, por vezes, com aquilo que pretendemos descrever.
} 
subcategorias são descritas de modo mais longo e exaustivo. Em Ryder (2001, p. 8), as categorias com vínculo mais estreito com a temática $\mathrm{NdC}$ são: coleta e avaliação de dados; interpretação de dados; modelagem em ciência; incerteza em ciência; e comunicação científica em domínio público ${ }^{4}$. Enquanto aspectos relacionados à Sociologia da ciência aparecem mais fracamente representados nos estudos de Ryder (2001, 2002), parece-nos evidente que a VC não considera de modo mais profundo os processos da ciência, tal qual surgem nas análises dos demais trabalhos citados.

Esse é um ponto importante. Embora McComas et al. (1998b, p. 6) afirmem: "Não há uma única maneira de se fazer ciência (portanto, não há método científico universal passo-apasso)", a informação sobre métodos não avança desse ponto. De modo semelhante, embora possamos ler em McComas (2008, p. 251) que: “(A) A Ciência produz, demanda e se baseia em evidência empírica" e "(B) A produção do conhecimento em ciência partilha muitos fatores comuns e hábitos mentais, normas, pensamento lógico e métodos, tais como observação cuidadosa e registro de dados, veracidade nos relatos etc.", uma descrição mais detalhada do que seriam tais métodos ou daquilo que está envolvido na coleta e interpretação de dados está ausente. Em Driver et al. (1996, p. 144), p. ex., isso surge na categoria "avaliação da evidência" que, entre outros aspectos, destaca ser importante compreender: “(...) os conceitos de acurácia, confiabilidade, validação e replicabilidade (...); os meios de organizar a coleta de dados de modo a que inferências lógicas possam ser feitas acerca da influência de variáveis específicas ou de características de um sistema (...)”. Já em Ryder (2001, p. 8) a consideração de processos da ciência encontra-se bem mais explicitada em algumas das próprias categorias síntese do estudo: Coleta e avaliação de dados (Avaliar a qualidade dos dados e Design do estudo); Interpretação de dados (Avaliar a validade da interpretação em ciência; correlação e causalidade; consideração de explicações alternativas; horizonte temporal; interpretação envolve as fontes do conhecimento em adição aos dados; múltiplas interpretações em ciência).

Não nos parece ser o caso de minimizar tais diferenças de caminho, pontos de partida e conclusões, afirmando, p. ex., que a discussão dos processos da ciência ${ }^{5}$ está presente implicitamente na VC. As diferenças são mais profundas do que isso e remetem diretamente a uma consideração daquilo que deve ser objeto de ensino nas salas de aula e deverá, de um modo ou de outro, estar presente nos currículos. Nesse ponto vale a pena fazermos uma breve referência ao trabalho de Osborne et al. (2003), que tenta conciliar a VC com os resultados de um estudo empírico com experts de diversas áreas (educadores da ciência; cientistas; historiadores, filósofos e sociólogos da ciência; experts engajados no trabalho de melhorar a compreensão pública

\footnotetext{
4 No estudo de 2002, vários dos objetivos de aprendizado epistêmicos originais foram retirados e houve uma reclassificação, o que levou à seguinte categorização: acesso à qualidade dos dados; design do estudo; explicações científicas; incerteza em ciência; e comunicação científica (RYDER, 2002, p. 643).

5 É importante deixar claro que, quando falamos em "processos da ciência", não estamos tratando de estratégias didáticas nem misturando a temática $\mathrm{NdC}$ com a perspectiva da investigação científica (scientific inquiry), tal como Abd-El-Khalick (2012a) e Lederman e colaboradores (2014) alertam. Estamos nos referindo a uma reflexão explícita sobre os métodos e processos da ciência.
} 
da ciência; e professores de ciência experientes). Apesar de haver certa correspondência entre certos princípios de $\mathrm{NdC}$ (tenets) e temas emergentes do estudo com a metodologia Delphi (OSBORNE et al., 2003, p. 713), é justamente com referência aos processos e métodos da ciência que a correspondência parece forçada: a ideia de "análise e interpretação de dados" (e a descrição do que isso significa) são mais amplas do que a afirmação da VC de que "a ciência se baseia em evidência empírica". O mesmo vale para o tema "método científico e testagem crítica".

Tais diferenças não se dão ao acaso. Ao contrário, relacionam-se com o próprio entendimento do que significa e do que deve ser incluído sob a denominação de "natureza da ciência". Em geral, os partidários da VC e boa parte dos trabalhos que partem ou tem como referência documentos educacionais norte-americanos costumam compreender 'natureza da ciência' como 'natureza do conhecimento científico', separando-a da ideia de investigação (science as inquiry) e, assim, deixando de lado aspectos relativos aos processos e métodos da ciência. Para eles, natureza da ciência e conhecimento sobre pesquisa/investigação são dois conjuntos diferentes de conhecimentos, embora com sobreposições (a esse respeito ver, p. ex., LEDERMAN; BARTOS; LEDERMAN, 2014). Por outro lado, adotando um entendimento ampliado de 'natureza da ciência', outros trabalhos, como os de Driver et al. e Ryder, citados anteriormente, costumam considerar os processos e métodos da ciência como parte do conhecimento sobre $\mathrm{NdC}$.

Outro aspecto dessa discussão refere-se à terminologia presente nos diversos trabalhos. Enquanto a expressão "natureza da ciência" ("nature of science") tornou-se lugar comum na literatura especializada da área de ensino de ciências, podendo ser considerada um slogan (uma "catch phrase", segundo Hipkins et al. 2005), outros estudos preferem a expressão "saber sobre a ciência" ("knowledge about science"), "como a ciência funciona" ("how science works"), "epistemologia da ciência" ("epistemology of science") ou mesmo "ideias sobre a ciência" ("ideas-about-science"). Isso pode ser visto, inclusive, na escolha feita pelos autores em relação às palavras-chave, em cada trabalho (recentemente, um Editorial da Science \& Education (KROGH; NIELSEN, 2013) evidenciou a existência de um debate em torno dessa questão terminológica).

Todas essas diferenças estão relacionadas, a nosso ver, à própria origem e à formação profissional dos pesquisadores em questão, refletindo a história desse debate acerca do ensino sobre as ciências ao longo dos anos e ao redor do mundo. Se olharmos Jenkins (2013), p. ex., teremos um vislumbre de como essa discussão atravessou as diversas décadas desde o início do século XX no Reino Unido, e de como o "tom” dessa temática foi se transformando. Também em Taber (2008) encontramos dados que evidenciam a transformação curricular (e terminológica) dessa temática no Reino Unido. Fica então a suspeita: estamos falando a mesma coisa quando nos referimos à "natureza da ciência"? A própria expressão pode estar associada a as- 
pectos diferentes a depender da origem, da experiência, da posição profissional e dos pressupostos (ontológicos, epistemológicos etc.) de quem fala ${ }^{6}$. Desenvolvemos esse argumento de modo mais extenso, a partir de um referencial da Sociologia da ciência, em outro trabalho (MARTINS, 2015).

As diferenças até aqui apontadas (em rotas, pontos de partida, terminologia e conclusões) sugerem certa limitação da perspectiva de um consenso, ainda que restrita à inserção curricular de conteúdos de NdC. Essa limitação se torna mais evidente quando nos voltamos a certas críticas endereçadas à VC. Por exemplo, em relação ao fato de que, dentre os oito documentos oficiais considerados para o estabelecimento dos princípios de $\mathrm{NdC}$ (tenets), nenhum pertencer a Europa continental, América Latina, África ou mesmo Ásia ${ }^{7,8}$. Ou então em relação ao fato de a ideia de "modelagem" na ciência não ser enfatizada significativamente. Afinal, uma compreensão de que a ciência trabalha com modelos, o que são modelos etc. é de fundamental importância em qualquer discussão da natureza da ciência (a palavra "modelo" não surge nos "princípios", embora uma discussão dessa natureza possa ser associada à ideia de "observação carregada de teoria", p. ex., ou a outros aspectos da VC).

Outra crítica é feita por Clough (2006, 2007). Mesmo assumindo que certos aspectos de NdC são, dentro de um grau aceitável, isentos de controvérsias, Clough (2006) afirma que:

\begin{abstract}
[...] boa parte são contextuais com exceções importantes e complexas. Onde o consenso não existe, a chave é transmitir uma pluralidade de pontos de vista para que professores de ciência e estudantes venham a compreender a importância das questões e complexidades relativas à NdC. Mesmo em questões de NdC que tenham ampla concordância, uma compreensão conceitual em vez de um conhecimento declarativo deve ser buscada. Isso é crítico, uma vez que a meta de uma educação progressiva, que inclua uma compreensão da natureza da ciência, não é doutrinar, mas educar estudantes sobre questões relevantes, sua natureza contextual e as razões para diferentes perspectivas (MATTHEWS, 1997) (CLOUGH, 2006, p. 463-464, tradução nossa).
\end{abstract}

\footnotetext{
${ }^{6}$ Embora estejamos nos referindo a pesquisadores envolvidos com a temática, é interessante ver o efeito da expressão "natureza da ciência" entre pesquisadores da área de ensino de ciências, mas não familiarizados com a temática. Nossa própria experiência tem mostrado que o termo "natureza" não é compreendido imediatamente e costuma causar algum tipo de estranhamento ("O que você está entendendo por 'natureza' da ciência? É a mesma coisa que 'História e Filosofia da Ciência'?’’ é algo que já ouvimos diversas vezes).

${ }^{7}$ Os documentos analisados são dos Estados Unidos (4), Canadá (1), Austrália (1), Nova Zelândia (1) e Inglaterra/País de Gales (1) (McCOMAS; OLSON, 1998, p. 42-43). Os autores reconhecem a possibilidade de que esses documentos, em algum grau, tenham sido influenciados uns pelos outros, assim como a pertinência de se investigar documentos de outras línguas e de culturas não ocidentais (McCOMAS; OLSON, 1998, p. 51).

8 Aliás, Good e Shymansky (2001) analisam dois desses documentos (Benchmarks for Science Literacy, 1993, e National Science Education Standards, 1996) e evidenciam como as afirmações neles presentes podem levar a leituras praticamente antagônicas, a depender do ponto de vista de quem lê. Tanto uma visão moderna/realista quanto uma visão pós-moderna/relativista da ciência seriam permitidas, podendo causar confusão entre professores de ciências, p.ex.
} 
Clough (2007) também sinaliza para o fato de que os princípios de $\mathrm{NdC}$ podem ser facilmente distorcidos por pesquisadores, professores e estudantes, tornando-se algo a ser transmitido - mais do que investigado - em sala de aula. Propõe que aspectos da natureza da ciência sejam abordados como questões, em vez de "princípios" (p. ex. "Em que sentido o conhecimento científico é tentativo/provisório? Em que sentido ele é durável?" em vez do princípio “O conhecimento científico, enquanto durável, tem caráter tentativo/provisório").

Allchin $(2011,2012)$ também critica o tipo de conhecimento declarativo presente nas listas de princípios de NdC. Para esse autor, essas listas são "inerentemente incompletas e insuficientes para uma alfabetização científica funcional" (ALLCHIN, 2011, p. 524). Elas omitem muitos itens relevantes, como, por exemplo, o papel significativo da credibilidade, a interação social dos cientistas, o processo de revisão por pares, vieses cognitivos, fraude, entre outros (ALLCHIN, 2004, 2011). Allchin (2011) defende que se considere a alfabetização científica em contex to e que se explorem estudos de caso contextualmente ricos. Argumenta a favor de um método para acessar o conhecimento sobre $\mathrm{NdC}$ que evitaria avaliar afirmações declarativas, tais como as presentes nos princípios de NdC. O autor sugere uma reconfiguração da NdC para torná-la sensível a todas as dimensões que envolvem a confiabilidade da prática científica, o que ele denomina de "Ciência completa" ("Whole Science"):

A natureza da ciência, então, não pode ser adequada ou completamente expressa por uma lista de princípios explícitos. Em vez disso, deve-se moldá-la como um conjunto de dimensões a respeito de como a confiabilidade é alcançada à medida que o conhecimento se desenvolve e como ela é preservada à medida que se move de um lugar para outro (ALLCHIN, 2011, p. 424, tradução nossa. Ver também Tabela 2, p. 525).

Irzik e Nola (2011) afirmam que a VC tem uma série de deficiências e fragilidades, sendo a principal delas a desconsideração das particularidades das diversas áreas das ciências. Aspecto semelhante já havia sido apontado por Rudolph (2000), para quem as particularidades das práticas das diversas ciências deveriam orientar uma compreensão da natureza da ciência, em vez de uma concepção universal do que a ciência é. Matthews (2012) segue na mesma direção e critica o que denomina de "Programa de Lederman", defendendo que os elementos de $\mathrm{NdC}$ sejam mais histórica e filosoficamente refinados. Propõe uma mudança de terminologia e de foco de pesquisa: de Natureza da Ciência (NdC) para Características da Ciência (CdC ou Features of Science (FOS), no original). Matthews defende que essa mudança para uma perspectiva mais contextual e heterogênea evitaria algumas armadilhas educacionais e filosóficas associadas à pesquisa em $\mathrm{NdC}$ :

(1) A mistura confusa de características epistemológicas, sociológicas, psicológicas, éticas, comerciais e filosóficas numa única lista de $\mathrm{NdC}$.

(2) O privilégio de um lado daquilo que envolve argumentos controversos e muito debatidos sobre a metodologia ou 'natureza' da ciência.

(3) O pressuposto de soluções particulares do problema da demarcação. 
(4) O pressuposto de que a aprendizagem da NdC pode ser julgada e avaliada pela capacidade dos estudantes de identificar algumas afirmações declarativas sobre $\mathrm{NdC}$ (MATTHEWS, 2012, p. 4, tradução nossa).

Outros autores, como Duschl e Grandy (2013), consideram mais frutífero, para propósitos educacionais, aproximar NdC e investigação. Nesse sentido, uma definição mais ampla daquilo que se compreende por "natureza da ciência" englobaria não apenas a natureza do conhecimento científico, mas também aquilo que costuma ser compreendido como um saber sobre a pesquisa. Preocupados com o efeito curricular do que consideram ser "ideias datadas" sobre a natureza da ciência, opõem uma visão fundamentada em Princípios Heurísticos Baseados no Consenso (associada à VC) a uma visão fundamentada na ideia de Construir e Refinar Práticas Científicas Baseadas em Modelos. Para os autores, que partem da perspectiva oferecida pela Visão Naturalizada da Filosofia da Ciência, não deveria haver separação entre NdC e investigação (inquiry), e o aprendizado sobre $\mathrm{NdC}$ seria beneficiado por meio da experiência de "fazer ciência".

Mesmo aceitando as limitações e simplificações inerentes à VC, assim como a ideia de que os princípios de $\mathrm{NdC}$ são afirmações de caráter geral que requerem detalhamento ulterior, há também a possibilidade de que as limitações impostas pela forma assumida pela VC (conhecimento declarativo, listas de princípios de $\mathrm{NdC}$ ) levem a problemas de conteúdo. É o que veremos brevemente na seção seguinte.

\section{Alguns outros problemas e o relativismo}

Tomemos, p. ex., a ideia de que "A ciência tem se desenvolvido por meio de 'ciência normal' e de 'revolução', como descrito por Kuhn (1962)", como aparece em McComas (2008, p. 251). A particular visão da ciência fornecida por Thomas Kuhn, embora possa ter um número grande de adeptos na área de ensino de ciências, está longe de ser unânime, e essa particular epistemologia traz em seu bojo várias outras noções controversas (p. ex.: incomensurabilidade, paradigma). É totalmente lícito que alguém tenha outra visão do desenvolvimento histórico da ciência e não seja favorável à concepção de "revolução". Um adepto da epistemologia de Imre Lakatos e da metodologia dos programas de pesquisa científica talvez não fique confortável com essa afirmação, por exemplo. Assim, um compromisso com uma particular epistemologia nos parece ser um problema'.

"A ciência tem um componente criativo" é um aspecto bastante ressaltado pela VC. Entretanto, se adotarmos (justamente) uma perspectiva kuhniana, somos levados a ver a prática cotidiana da ciência (típica da "ciência normal") tanto como algo que envolve imaginação e criatividade quanto como algo rotineiro e pouco criativo. $\mathrm{O}$ aspecto mais criativo da ciência

\footnotetext{
9 Ainda que a referência a Kuhn não apareça em todas as versões e que certamente existam outras perspectivas filosóficas subjacentes a VC, a crítica é endereçada aqui aos trabalhos onde esse "princípio" em particular é apresentado.
} 
estaria reservado, preferencialmente, à "ciência extraordinária" e aos períodos de revolução. Nesse sentido, chamar a atenção para o "componente criativo" da ciência não nos isenta de tratar o aspecto rotineiro, padronizado e pouco criativo que a atividade científica pode eventualmente assumir. O "princípio" apresenta-se, no mínimo, incompleto.

Outra afirmação importante diz que:

O conhecimento científico é tentativo, durável e autocorretivo (Isso significa que, embora a ciência não possa provar nada, as conclusões científicas ainda assim são valiosas e duradouras devido à forma pela qual elas são desenvolvidas, mas erros serão descobertos e corrigidos como parte do processo) (McCOMAS, 2008, p. 251, tradução e segundo grifo nossos).

Por um lado, é delicado afirmar que "erros" serão descobertos e corrigidos. Essa afirmação sugere algo inevitável, e não algo que "pode acontecer". Por outro lado, é bastante plausível que a afirmação leve a pensar que o cientista, normalmente, é capaz de descobrir e corrigir seus erros. Novamente aqui, se usarmos a epistemologia de Kuhn, surge certo ruído. Afinal, a prática da ciência normal evidencia como os "erros" dificilmente são corrigidos (e sequer percebidos) pelos praticantes. A famosa frase de Max Planck, de que uma nova verdade científica vinga não porque os oponentes veem a razão, mas porque eles finalmente morrem e uma nova geração cresce familiarizada com as novas ideias ${ }^{10}$, é emblemática aqui. Pode ser dito que a afirmação feita pela VC pressupõe um longo período de tempo. Ainda assim, a própria ideia de "erros" parece estar em desacordo com a noção kuhniana de incomensurabilidade e com a ideia de que cientistas que optam por diferentes paradigmas vivem em "mundos diferentes", além de sugerir - implicitamente - certa linearidade e cumulatividade na construção do conhecimento científico.

Allchin (2011, p. 528) chama a atenção para a possibilidade de "fogo amigo" quando consideramos afirmações de $\mathrm{NdC}$ "tipo-declarativas" em contextos da vida real. A ideia de que "a ciência é tentativa", p. ex., pode ser usada com a intenção de enfraquecer os argumentos e conclusões da ciência. Allchin (2011) também aponta certos problemas específicos com os tenets, tais como a difícil conciliação a ser feita pelos estudantes de ideias como "a investigação é carregada de teoria" com "cientistas são criativos" ou "o conhecimento científico é durável" com "o conhecimento científico é tentativo", por exemplo.

De modo um pouco mais problemático, temos a afirmação: "A ciência tem um elemento subjetivo. Em outras palavras, ideias e observações em ciência são 'carregadas de teoria"”. Concordamos com a ideia de que observações em ciência sejam "carregadas de teoria". No entanto, parece-nos muito diferente dizer que a ciência tem um elemento subjetivo. Essas

\footnotetext{
10 "Uma nova verdade científica não triunfa convencendo seus oponentes e fazendo com que vejam a luz, mas, antes, porque seus oponentes finalmente morrem e uma nova geração cresce familiarizada com ela" (PLANCK, 1950, p. 33-34, tradução nossa).
} 
duas afirmações não dizem a mesma coisa. Um aspecto bastante ressaltado pela Sociologia da ciência e mesmo pelas discussões sobre $\mathrm{NdC}$ na área de ensino de ciências é a maneira pela qual a ciência se constitui em conhecimento socialmente partilhado, construído coletivamente num processo de diálogo e, portanto, intersubjetivo. O conhecimento científico é referendado pela comunidade científica, num processo complexo em que tem lugar a revisão pelos pares. Ao igualarmos "carregada de teoria" com "elemento subjetivo", ficamos com a impressão de que as teorias com quais estabelecemos nosso particular olhar para o real - partilhadas e construídas socialmente, intersubjetivamente - são subjetivas ou carregadas de aspectos idiossincráticos. E que as teorias, portanto, são individuais, pessoais.

Essa visão flerta perigosamente com uma visão de senso comum que iguala "teoria" a mera "opinião", "visão" pessoal. Não é raro ouvirmos algo como: "Eu tenho uma teoria de que vai chover amanhã"; ou: "Um conselho é só teoria; viver é muito diferente". Esse uso comum do termo pode trazer consequências ruins para o ensino de ciências. P. ex., no conhecido debate entre criacionismo e teoria da evolução, quando esta última passa a ser vista como uma simples "teoria" (=opinião). Não queremos dizer aqui que a VC não esteja atenta a tudo isso, ou que use o termo "teoria" em sentido comum. A própria defesa de uma distinção entre leis e teorias (um dos NOS tenets) apontaria na direção contrária. Mas a afirmação original de que "A ciência tem um elemento subjetivo" pode dar margem a um entendimento equivocado.

Chegamos com isso a uma questão importante, embora sutil: a VC opõe-se a uma visão positivista, realista ingênua e de senso comum da ciência, tal qual caracterizada na Introdução desse trabalho. Desconstruir essa visão tem sido parte da meta de um ensino sobre as ciências. Em seu lugar, a VC propõe uma visão que, embora não seja coesa e monolítica, parece situar-se no âmbito de um relativismo moderado ao apontar, p. ex., o aspecto provisório do conhecimento, a inexistência de um método único e rígido, a existência de vieses teóricos na observação e experimentação, as influências históricas, sociais e culturais da prática científica. Mas em que medida a apresentação de uma visão relativista moderada não resultará na adoção de um relativismo exacerbado?

Alguns autores chamaram, de uma forma ou de outra, a atenção para esse problema do relativismo. Matthews (1998), p. ex., no prefácio do livro editado por McComas, aponta a necessidade de perceber a ciência como um tema complexo, no contexto da desconstrução de "mitos da ciência" e da apresentação de uma "mais complexa compreensão da ciência":

Mas o reconhecimento dessa complexidade não significa simplesmente que 'tudo vale', ou que 'todas as ideias e visões de mundo são iguais', ou que 'a ciência é apenas uma construção social'. O reconhecimento de que a ciência é uma construção humana complexa de modo algum implica o relativismo e instrumentalismo frequentemente associados à filosofia construtivista (MATTHEWS, 1998, p. xvi, tradução nossa).

Numa direção semelhante, outros autores defendem que se construa uma imagem da ciência realista e racionalista moderada, sem perder de vista as limitações e os aspectos éticos 
e humanos da ciência, mas destacando suas realizações intelectuais e materiais (IZQUIERDO; ADÚRIZ-BRAVO, 2003; ADÚRIZ-BRAVO; ROSALES, 2011).

$O$ problema do relativismo surge com outra roupagem na discussão acerca das diversas vertentes do construtivismo (radical, social etc.). Mas, do mesmo modo, uma crítica a um relativismo exacerbado parece ser preocupação corrente, a qual compartilhamos. Citemos alguns trabalhos da década de 1990, quando vários autores posicionaram-se criticamente em relação à epistemologia construtivista: Matthews (1994b), p. ex., argumenta que a premissa de que a mente é ativa na aquisição do conhecimento teria levado à conclusão epistemológica (relativista), endêmica nos escritos construtivistas, de que não podemos conhecer a realidade. Esse autor defende uma "epistemologia objetivista" em lugar de um relativismo exacerbado que levaria à impossibilidade do conhecimento. Já Osborne (1996) avalia que o peso excessivo na ideia de "construção de conceitos" acabou por levar o construtivismo a uma negação da objetividade e racionalidade da ciência. Analisando o construtivismo radical e o social, conclui que eles não conseguiriam distinguir a ciência de outras formas de conhecimento, e levariam a uma visão de que a ciência é um empreendimento irracional. Esse autor defende que uma epistemologia realista, ainda que moderada, seria a mais adequada e apresentaria implicações pedagógicas diferentes daquelas do construtivismo. Nessa mesma linha, Ogborn (1997) critica a base epistemológica do construtivismo, caracterizando-a como uma estranha mistura entre idealismo e empirismo. Para ele, o construtivismo apresenta a ciência como conjunto de estórias arbitrárias da mente, sem sérias relações com uma realidade independente de nós. Kragh (1998) posiciona-se contra uma epistemologia que considera relativista ou agnóstica, defensora de que o conhecimento origina-se mais no social do que na natureza. Ataca a posição de certos construtivistas sociais, acusando-os de (na prática) reviver movimentos "anticientíficos". Defende que a identificação entre o laboratório escolar e o laboratório da ciência "real" pouco esclarece sobre a natureza da ciência, devendo-se apresentar um quadro mais realista de como os cientistas trabalham.

Não temos a pretensão de entrar em debates filosóficos. Porém, cabe dizer que o relativismo, na medida em que faz o conhecimento humano depender de fatores históricos, políticos, econômicos, sociais, do espírito da época etc., deveria vir - ao menos do ponto de vista da educação científica - acompanhado da discussão de até que ponto a natureza impõe restrições sobre o conhecimento construído.

Trata-se, num certo sentido, de resgatar o que Matthews denomina de "ideia universalista central":

A ideia universalista central é que o mundo material, em última instância, julga a adequação das nossas descrições sobre ele. Os cientistas propõem, mas, no final, após debate, negociação e todo o resto, é o mundo que dispõe (MATTHEWS, 1994a, p. 182, tradução nossa). 
Um relativismo exacerbado pode levar a atitudes anticientíficas e ao irracionalismo. Mesmo Paul Feyerabend percebeu o perigo de uma posição demasiada afastada de uma perspectiva racional, ao rever suas posições defendidas em 1970:

Os tempos mudaram. Considerando algumas tendências na educação norte-americana ('politicamente correto', menus acadêmicos etc.), em filosofia (pós-modernismo) e no mundo como um todo, eu penso que deveria ser dada à razão um peso maior, não porque ela é e sempre foi fundamental, mas porque ela parece ser necessária, em circunstâncias que ocorrem com maior frequência hoje (mas podem desaparecer amanhã), para criar uma abordagem mais humana (FEYERABEND, 1993, p. 13 , nota de rodapé 12 , tradução nossa).

Não estamos defendendo aqui que a VC manifeste um tipo de relativismo exacerbado. Sem dúvida que esse tipo de visão não pode ser imputado a ela. O que estamos chamando a atenção é para o fato de que, considerada em seu conjunto (ou seja: privilegiando a apresentação de frases curtas e de caráter geral sobre a ciência; trazendo ideias como "a ciência tem um elemento subjetivo"; não abordando em profundidade os processos da ciência), a VC pode, eventualmente, contribuir para um tipo de relativismo inadequado para uma apreciação da ciência enquanto empreendimento humano epistemologicamente diferente do conhecimento se senso comum e de outras formas de conhecimento.

Nossa preocupação é de natureza semelhante à exposta por Clough (2007) na seguinte passagem:

Princípios sobre a natureza da ciência podem ser facilmente mal compreendidos e usados de modo abusivo. Estudantes com frequência veem as coisas como preto ou branco. Por exemplo, quando discutia o caráter histórico provisório da ciência, há alguns anos, ao ensinar ciências na escola secundária, meus estudantes saltavam do extremo de ver a ciência como conhecimento absolutamente verdadeiro para o outro extremo, como conhecimento não confiável. Era necessário muito esforço para movêlos para uma posição mais intermediária. Colegas contaram-me sobre estudantes que perguntavam por que eles tinham que aprender o conteúdo científico se ele estava sempre mudando (CLOUGH, 2007, tradução nossa).

Consideramos que a desconstrução de concepções equivocadas de ciência deve vir acompanhada de uma cuidadosa construção de visões mais atuais e adequadas. E não de visões que levem a atitudes anticientíficas. Caso contrário, corremos o risco de "jogar o bebê com a água do banho".

A conclusão não é a de que a VC deva ser descartada ou desprezada. Não estamos contra a VC, a sabedoria partilhada que ela representa ou o esforço de estabelecer conteúdos significativos para o ensino da temática NdC. Pelo contrário, acreditamos que os pesquisadores que trabalham nessa direção trouxeram contribuições fundamentais para o avanço do conhecimento na área de educação científica. Nosso ponto central, aqui, é destacar que a VC, devido à 
sua forma e ao seu conteúdo, tem enfrentado críticas. E que tais críticas, ainda que as listas de tenets possam ser reinterpretadas, tem como base aquilo que está efetivamente publicado e que pode funcionar como referente para instrução.

Dada a complexidade desse debate, como o conhecimento sobre NdC oriundo da pesquisa em ensino de ciências pode orientar o desenvolvimento de currículos? Consideraremos essa questão na seção seguinte.

\section{NdC no currículo: uma tarefa impossível?}

O historiador da ciência Stephen Brush, em 1974, escreveu um provocante trabalho na Science que se tornou famoso pelo seu título: "Should the History of Science be rated X?" (BRUSH, 1974). Ele estava preocupado que o uso didático da história da ciência comprometesse o recrutamento de cientistas, embora os não-cientistas pudessem ganhar uma apreciação adequada das dimensões humanistas da ciência. Mais recentemente, a provocação foi renovada com referência à sociologia da ciência (ALLCHIN, 2004), cuja reconciliação com a filosofia da ciência poderia informar melhor a educação científica acerca da temática $\mathrm{NdC}$. Com suas nuances e diferenças, ambos os trabalhos sinalizam para dificuldades e polêmicas inerentes à inserção de um saber sobre a ciência na educação científica. Da mesma forma, poderíamos perguntar se a $\mathrm{NdC}$ deveria ser proibida para menores...

Segundo Jenkins (2013), talvez seja infrutífero tentar definir um currículo que considere adequadamente as questões sobre $\mathrm{NdC}$, considerando o quadro múltiplo da natureza da atividade científica apresentado pelos pesquisadores. Por outro lado, estamos de acordo com Abd-El-Khalik (2012a e 2012b) e com os defensores da VC de que é melhor algum ensino sobre $\mathrm{NdC}$, ainda que com limitações, do que deixarmos de agir e permitirmos a continuidade da propagação de visões deturpadas e equivocadas da ciência.

Entretanto, o que foi abordado nas seções anteriores nos leva a concluir que uma consideração mais adequada da temática $\mathrm{NdC}$ nos currículos de ciências deveria partir de uma perspectiva mais aberta, plural e heterogênea. Nenhuma lista será exaustiva e sempre trará problemas. Também não se trata de afirmar que alguns aspectos seriam consensuais e outros, não ${ }^{11}$.

Parece-nos claro, a esta altura, que a ideia de questões - em vez de "princípios" (CLOUGH, 2007) - e a ideia de semelhança familiar (IRZIK; NOLA, 2011) podem ser pontos de partida interessantes para se pensar acerca de conteúdos de $\mathrm{NdC}$. Um passo seguinte importante seria construir propostas especialmente desenhadas para atender aos diversos níveis de ensino e às várias disciplinas científicas (aqui, a ideia de semelhança familiar ganha força, pois

\footnotetext{
11 Eflin e colaboradores (1999) - todos filósofos - defendem, ao analisarem a crítica de Alters (1997) à VC, que existem áreas de consenso e de dissenso sobre a NdC. Essa posição, a nosso ver, não resolve integralmente os problemas mais gerais de forma e de conteúdo associados ao conhecimento declarativo dos tenets. Mas estamos de acordo com esses autores quando afirmam que: "Assim como os educadores em ciência realçam que a ciência é mais do que uma coleção de fatos, enfatizamos que uma posição filosófica sobre a natureza da ciência é mais do que uma lista de princípios” (EFLIN; GLENNAN; REISCH, 1999, p. 112, tradução nossa).
} 
as características das diversas ciências, em relação à temática $\mathrm{NdC}$, são diferentes). Como afirma Taber (2008), deve-se buscar uma "simplificação intelectualmente honesta" quando se pensam os conteúdos a serem ensinados.

Há várias abordagens válidas. Para nós, antes de chegarmos a algo como "princípios de NdC", parece razoável pensar em alguma coisa como "temas de $\mathrm{NdC}$ ". Os diversos trabalhos da literatura sugerem caminhos possíveis. Seguindo mais de perto o livro de Driver et al. (1996), identificamos dois eixos principais: o eixo histórico e sociológico e o eixo epistemológico. $\mathrm{O}$ primeiro eixo agruparia temas relativos ao papel do indivíduo e da comunidade científica; a intersubjetividade; questões morais, éticas e políticas; influências históricas e sociais; ciência como parte da cultura; comunicação do conhecimento. O segundo eixo, mais amplo, agruparia temas relativos à origem do conhecimento (experiência x razão; papel da observação, da experiência, da lógica e do pensamento teórico; influência da teoria sobre o experimento), aos métodos, práticas, procedimentos e processos da ciência (coleta, análise e avaliação de dados; inferência, correlação e causalidade; modelagem em ciência; papel da imaginação e criatividade; natureza da explicação), e ao conteúdo/natureza do conhecimento produzido (papel de leis e teorias; noção de modelo; semelhanças e diferenças entre ciência e outras formas de conhecimento) ${ }^{12}$.

Sem a pretensão de criar listas ou representar essa ideia de forma exaustiva, indicamos na Tabela 1 os dois eixos apontados anteriormente, assim como exemplos de temas que poderiam ser explorados.

Esses dois grandes eixos estão, obviamente, inter-relacionados. A divisão é, até certo ponto, artificial, se entendermos que os aspectos propriamente epistêmicos e que caracterizam a "natureza" do conhecimento produzido provêm de uma construção que é coletiva (intersubjetiva), histórica e social. O tema da origem do conhecimento ( $2^{\circ}$ eixo), p. ex., pode ser colocado em termos de como isso tem sido visto ao longo da evolução histórica e social da ciência ( $1^{\text {o }}$ eixo). Da mesma forma, um tema como "finalidades da ciência" envolve tanto a relação ciência $\leftrightarrow$ sociedade ( $1^{\circ}$ eixo), que moldou historicamente os objetivos associados à construção desse conhecimento, quanto o tipo de relação sujeito(s) $\leftrightarrow$ objeto(s) ( $2^{\circ}$ eixo), base dessa construção. Esse tema também pode se relacionar com a ideia de "natureza da explicação em ciência" ( $2^{\circ}$ eixo), uma vez que o modo como se dão as explicações e justificativas do conhecimento científico relaciona-se com os objetivos e finalidades associados a esse conhecimento.

\footnotetext{
12 Essa divisão em dois grandes eixos assemelha-se, nesse nível, àquela feita por Irzik e Nola em trabalho recente, que desconhecíamos quando criamos nossa classificação. Esses autores propõem uma divisão ampla entre ciência como um sistema cognitivo-epistêmico de pensamento e prática, de um lado, e ciência como um sistema socialinstitucional, de outro (IRZIK; NOLA, 2014, p. 1003).
} 
Tabela 1 - Eixos para discussão de conteúdos de NdC e exemplos de temas de NdC.

\begin{tabular}{|c|c|c|c|}
\hline \multirow{2}{*}{$\begin{array}{c}\text { Eixo sociológico e } \\
\text { histórico }\end{array}$} & \multicolumn{3}{|c|}{ Eixo epistemológico } \\
\hline & $\begin{array}{l}\text { Problema da origem } \\
\text { do conhecimento (ci- } \\
\text { entífico) }\end{array}$ & $\begin{array}{l}\text { Métodos, procedi- } \\
\text { mentos e processos } \\
\text { da ciência }\end{array}$ & $\begin{array}{l}\text { Conteúdo / natu- } \\
\text { reza do conheci- } \\
\text { mento produzido }\end{array}$ \\
\hline $\begin{array}{l}\text { Papel dos indiví- } \\
\text { duos/sujeitos e da } \\
\text { comunidade cientí- } \\
\text { fica } \\
\text { - Intersubjetividade } \\
\text { - Influências históri- } \\
\text { cas e sociais } \\
\text { - Questões morais, } \\
\text { éticas e políticas } \\
\text { - A ciência como } \\
\text { parte de uma cul- } \\
\text { tura mais ampla } \\
\text { - Objetivos da ciên- } \\
\text { cia / objetivos dos } \\
\text { cientistas } \\
\text { - Comunicação do } \\
\text { conhecimento cien- } \\
\text { tífico dentro da co- } \\
\text { munidade científica } \\
\text { e em domínio pú- } \\
\text { blico } \\
\text { - Controvérsias his- } \\
\text { tóricas e contempo- } \\
\text { râneas na ciência } \\
\text { - Ciência e outros ti- } \\
\text { pos de conheci- } \\
\text { mento } \\
\text { - Ciência e tecnolo- } \\
\text { gia } \\
\text { \{Diferenças entre } \\
\text { as áreas / discipli- } \\
\text { nas científicas\} }\end{array}$ & $\begin{array}{l}\text { - Sujeito(s) e ob- } \\
\text { jeto(s) do conheci- } \\
\text { mento científico } \\
\text { - Empírico vs. teó- } \\
\text { rico } \\
\text { - Papel da observa- } \\
\text { ção, experimenta- } \\
\text { ção, lógica, argu- } \\
\text { mentos racionais e } \\
\text { pensamento teórico } \\
\text { - Influências teóricas } \\
\text { sobre observações } \\
\text { e experiências } \\
\text { - Ciência e outros ti- } \\
\text { pos de conheci- } \\
\text { mento } \\
\text { - } \text { \{Diferenças entre } \\
\text { as áreas / discipli- } \\
\text { nas científicas\} }\end{array}$ & $\begin{array}{l}\text { - Coleta, interpreta- } \\
\text { ção, análise e ava- } \\
\text { liação dos dados } \\
\text { - } \text { Modelagem } \\
\text { - Observação e in- } \\
\text { ferência } \\
\text { - Hipóteses, previ- } \\
\text { sões e testes } \\
\text { - Correlação e cau- } \\
\text { salidade } \\
\text { - Natureza da expli- } \\
\text { cação em ciência } \\
\text { - Avaliação de teo- } \\
\text { rias } \\
\text { - Papel das analo- } \\
\text { gias, imaginação e } \\
\text { criatividade } \\
\text { - Visão do senso } \\
\text { comum sobre o } \\
\text { método científico } \\
\text { (sequência passo- } \\
\text { a-passo) } \\
\text { - Ciência e outros } \\
\text { tipos de conheci- } \\
\text { mento } \\
\text { - \{Diferenças entre } \\
\text { as áreas / discipli- } \\
\text { nas científicas\} }\end{array}$ & $\begin{array}{l}\text { - Leis e teorias } \\
\text { - Postulados } \\
\text { - Noção de mo- } \\
\text { delo científico } \\
\text { - Papel da Mate- } \\
\text { mática } \\
\text { - Poder e limita- } \\
\text { ções do conheci- } \\
\text { mento científico } \\
\text { - Ciência e outros } \\
\text { tipos de conhe- } \\
\text { cimento } \\
\text { - Ciência e tecno- } \\
\text { logia } \\
\text { - } \text { \{Diferenças en- } \\
\text { tre as áreas / } \\
\text { disciplinas cien- } \\
\text { tíficas\} }\end{array}$ \\
\hline
\end{tabular}

Um tema que pode ser abordado sob diversas perspectivas é "ciência e outras formas de conhecimento". Considerado do ponto de vista histórico e sociológico ( $1^{\mathrm{o}}$ eixo), diferenças históricas e sociais entre culturas distintas, bem como a gradativa consolidação da ciência como corpo de conhecimentos sistematizados, diferenciando-se ao longo dos séculos de outras formas 
de conhecimento, podem ser exploradas. Já do ponto de vista epistemológico ( $2^{\circ}$ eixo), os próprios métodos e processos da ciência são cruciais para entendermos as diferenças entre o conhecimento científico e saberes alternativos. Além disso, é justamente no que diz respeito à natureza/conteúdo do conhecimento produzido que características distintivas da ciência poderiam ser exploradas, tais como seu caráter conjectural, a noção de verdade (não absoluta), a ideia de rupturas e continuidades, a natureza da mudança em ciência, as ideias de predição, consistência interna e simplicidade, assim como características da linguagem científica.

Embora não tenhamos indicado um eixo "ontológico" específico, questões de natureza ontológica poderiam ser abordadas sob o tema sujeito $(s)$ e objeto $(s)$ do conhecimento científico, dentro de problema da origem do conhecimento (científico) ( $2^{\circ}$ eixo). Discussões em torno da questão de quem são - e como se relacionam - os sujeitos e objetos do conhecimento científico levariam à discussão do tipo de entidades que compõem o universo da ciência.

É importante apontar que as diferenças entre áreas/disciplinas científicas é algo a ser explorado sob os diversos eixos e temas. Diferenças históricas ( $1^{\circ}$ eixo), assim como epistemológicas ( $2^{\circ}$ eixo), tais como as diversas metodologias usadas em diferentes áreas (in vitro, in vivo, testes duplo-cego etc.), seriam objeto de atenção. Nesse quesito, aspectos contextuais e específicos das diversas áreas poderiam ser mais bem explorados.

Um aprofundamento subsequente implicaria em, observando esses eixos e temas, descrever mais minuciosamente aquilo que deve ser ensinado. Esse caminho poderia nos levar a algo semelhante aos princípios de $\mathrm{NdC}$ propostos na $\mathrm{VC}$ (embora os trabalhos dessa linha não abordem exatamente esses mesmos eixos e temas). Num certo sentido, o trabalho de Abd-ElKhalic (2012a e 2012b) segue essa direção, ao sugerir uma estrutura curricular em espiral na qual um determinado aspecto da $\mathrm{NdC}$ seria abordado em níveis diferentes de profundidade ao longo da educação formal, nos diversos níveis de ensino. Esse caminho tem sua validade e pode, sem dúvida, ser um guia para a elaboração de currículos.

Consideramos, no entanto, que os próprios argumentos expostos nesse trabalho justificam outra abordagem. Um segundo passo na direção da articulação dessa abordagem envolveria, em nossa opinião, considerar tais temas a partir de questões, de modo similar ao proposto por Clough (2007) e já referido anteriormente. Tais questões contribuem para esclarecer o significado e o tratamento que podem ser dado aos temas, especificando um pouco mais aquilo que pode ser explorado em cada um deles e enfatizando o caráter investigativo que imaginamos que seu tratamento deve adotar. Novamente, aqui, é importante frisar que não se pretende apresentar essa ideia de modo exaustivo. Indicamos na Tabela 2 algumas questões que poderiam ser exploradas a partir dos temas: 
Tabela 2 - Exemplos de temas e questões de NdC.

\section{Eixo sociológico e histórico}

- Papel dos indivíduos/sujeitos e da comunidade científica Os cientistas trabalham isoladamente? O conhecimento científico é construído socialmente? Qual o papel do indivíduo? As "descobertas" são individuais ou coletivas? Que episódios históricos reforçam a ideia de trabalho individual ou a do grupo? Ao longo da história da ciência isso mudou?

- Intersubjetividade Há espaço para a subjetividade na ciência? É possível afastar a subjetividade do conhecimento construído pela ciência? Que procedimentos a comunidade científica utiliza para evitar isso? Tais procedimentos foram sempre os mesmos ao longo da história? Como evitar vieses pessoais? Conhecimento coletivo é conhecimento objetivo?

- Influências históricas e sociais Como o contexto histórico influencia a ciência? Quais as características da prática científica ao longo da história da humanidade? É possível dizer quando e onde começou o que chamamos hoje de ciência? De que forma o contexto social influencia a ciência? É possível isolar a prática da ciência de outras práticas sociais? A ciência é uma prática social?

- Questões morais, éticas e políticas

Aspectos morais e éticos orientam a prática científica? Eles diferem entre os países e as culturas? Há uma "ética da ciência"? Ela mudou ao longo da história? A ciência é masculina? Há fraude na ciência? A política influencia ou é influenciada pela ciência? De que maneiras? De que modo a economia afeta e é afetada pela ciência? Ao longo da história da ciência isso mudou?

- A ciência como parte de uma cultura mais ampla Pode-se falar em uma "cultura científica"? A ciência é parte de uma cultura mais ampla? Que diferenças existem entre essas duas posições? Como a cultura científica se relaciona com outras culturas? Há diferenças entre os países, no que se refere a uma "cultura cientifica"?

- Objetivos da ciência / objetivos dos cientistas Quais os objetivos da ciência? Eles são os mesmos objetivos dos cientistas, considerados isoladamente? Como essas coisas se articulam (hoje em dia e historicamente)? Quem define o que deve ser pesquisado?

- Comunicação do conhecimento científico dentro da comunidade científica e em domínio público De que forma os cientistas comunicam os resultados de suas pesquisas aos seus colegas? Que tipo de procedimentos e padrões existem para fazer isso? De que forma os cientistas se comunicam com o restante da sociedade? Há problemas ou dificuldades de comunicação entre os cientistas e o público em geral? Por que a comunicação dos resultados da ciência é importante?

- Controvérsias históricas e contemporâneas na ciência Os cientistas podem discordar entre si? Quais as possíveis razões para a ocorrência de uma discordância? Houve controvérsias na história da ciência? De que tipo? Ocorrem hoje em dia? De que modo as controvérsias são resolvidas?

- Ciência e outros tipos de conhecimento É possível diferenciar a ciência de outras formas de conhecimento? Que características são relevantes para isso? Essas diferenças sempre foram as mesmas ao longo da história? De que 
modo o contexto social influencia nessa diferenciação? A ciência pode ser considerada uma visão de mundo? Como ela difere de outras visões de mundo?

- Ciência e tecnologia

A ciência gera a tecnologia ou vice-versa? De que modo a história justifica uma ou outra posição? De que maneiras ciência e tecnologia se interrelacionam atualmente? Que papel o contexto social tem nessa relação?

- $\quad$ Diferenças entre as áreas / disciplinas científicas\}

\section{Eixo epistemológico}

Problema da origem do conhecimento (científico)

- Sujeito(s) e objeto(s) do conhecimento científico

Quem é o sujeito e quem é o objeto do conhecimento científico? É possível separá-los clara-

mente? Que "entidades" fazem parte do universo da ciência?

- Empírico vs. teórico

A experiência é a base para a construção do conhecimento científico? Qual o papel do pensamento teórico na construção do conhecimento científico? O que vem em primeiro lugar ou é mais importante: teoria ou experiência? Há "descobertas" sem conhecimentos teóricos prévios? É possível construir teorias sem uma base experimental?

- Papel da observação, experimentação, lógica, argumentos racionais e pensamento teórico Todos esses aspectos têm peso igual na construção do conhecimento científico? Qual o papel dos argumentos racionais e da lógica na interpretação de observações e experimentos? E o papel dos experimentos na sustentação de argumentos racionais e do pensamento teórico?

- Influências teóricas sobre observações e experiências

A teoria influencia a observação dos fenômenos elou a análise de experimentos? Como isso pode ser evidenciado? Há observações "neutras"?

- Ciência e outros tipos de conhecimento

É possível diferenciar a ciência de outras formas de conhecimento? Que características são relevantes para isso, em termos de sujeitos e objetos do conhecimento? Como a ciência e outras formas de conhecimento fazem uso de experiências e teorias?

- \{Diferenças entre as áreas / disciplinas científicas\}

Métodos, procedimentos e processos da ciência

- Coleta, interpretação, análise e avaliação dos dados

Como dados são coletados? Há uma ou diversas maneiras de tomar dados? Como definir amostras e identificar variáveis? Como os dados podem ser interpretados? Há várias maneiras de interpretar um mesmo conjunto de dados? Que técnicas e procedimentos existem para a análise de dados? Qual a natureza, as fontes e consequências da incerteza? Como avaliar a qualidade de um conjunto de dados? Quais as possíveis fontes de erros? Como evitar ou diminuir vieses na obtenção e no tratamento de dados?

- Modelagem

O que é um "modelo cientifico"? O que significa "modelar" um fenômeno? Por que esse é um procedimento importante na ciência?

- Observação e inferência

Que diferenças existem entre observação e inferência? Que papel elas têm na construção do conhecimento científico? 
- Hipóteses, previsões e testes

O que é uma hipótese? Qual a sua importância para a construção do conhecimento científico? Como testar hipóteses? Um teste tem caráter definitivo? O que fazer quando uma predição se mostra incorreta? O que se pode concluir quando uma predição é confirmada por testes?

- Correlação e causalidade

Que diferenças existem entre correlação e causalidade? Como diferenciá-las?

- Natureza da explicação em ciência

O que é uma explicação científica? Como ela se diferencia de outras formas de explicação da realidade? Como as explicações científicas se relacionam com as evidências empíricas e os argumentos teóricos?

- Avaliação de teorias

Como avaliar uma teoria? É possível comparar teorias diferentes com referência ao mesmo conjunto de fenômenos? Como decidir entre elas?

- Papel das analogias, imaginação e criatividade

O pensamento por analogia é usado em ciência? De que maneira? Os cientistas são criativos e imaginativos? Todos as etapas do trabalho do cientista envolvem imaginação e criatividade?

Há diferenças entre a imaginação e criatividade na ciência e em outras áreas?

- Visão do senso comum sobre o método científico (sequência passo-a-passo)

A ciência segue um método padrão em sua prática? Há alguma espécie de roteiro passo-apasso que oriente o cientista no seu dia-a-dia? Que etapas seriam essas?

- Ciência e outros tipos de conhecimento

É possível diferenciar a ciência de outras formas de conhecimento? Que características são relevantes para isso, em termos de métodos e procedimentos usados? Qual a relação entre os métodos e procedimentos da ciência e o grau de confiabilidade que podemos ter no conhecimento científico?

- $\quad$ Diferenças entre as áreas / disciplinas científicas\}

Conteúdo / natureza do conhecimento produzido

- Leis e teorias

O que caracteriza uma lei científica? O que caracteriza uma teoria científica? Leis e teorias, uma vez estabelecidas, são definitivas? Existe algum tipo de hierarquia entre "lei" e "teoria"? Que diferenças existem entre o uso cientifico e o uso, na linguagem comum, dos termos "lei" $e$ "teoria"?

- Postulados

A ciência faz uso de postulados? Em que situações? Qual a função dos postulados na construção do conhecimento científico? Qual a diferença entre postulado e hipótese?

- Noção de modelo científico

O que é um "modelo cientifico"? Qual a relação entre um modelo e o objeto em si? Qual a função dos modelos para o desenvolvimento de teorias? Quais os limites de aplicabilidade de um modelo?

- Papel da Matemática

A matemática é a linguagem da ciência? Pode-se fazer ciência sem matemática?

- Poder e limitações do conhecimento científico 
O conhecimento científico é verdadeiro? Ele pode ser provado? Ele é definitivo ou pode sofrer alterações ao longo do tempo? Quais os seus limites de aplicabilidade? Qual o papel do ceticismo na ciência?

- Ciência e outros tipos de conhecimento É possível diferenciar a ciência de outras formas de conhecimento? Que características são relevantes para isso? Em que aspectos o conteúdo e o discurso da ciência aproximam-se e afastam-se de outras perspectivas?

- Ciência e tecnologia

Quais as principais diferenças entre ciência e tecnologia? De que maneiras ciência e tecnologia se interrelacionam? O conhecimento científico, em seu conteúdo, incorpora o conhecimento tecnológico? Até que ponto?

- \{Diferenças entre as áreas / disciplinas científicas\}

Isso contempla, em certa medida, a flexibilidade necessária à incorporação da pluralidade de visões acerca dos aspectos de $\mathrm{NdC}$, principalmente no que diz respeito às diferentes disciplinas científicas. Adicionalmente, evita a formulação prematura de "princípios gerais" sobre $\mathrm{NdC}$ que não necessitam estar presentes nesse momento. A abordagem por temas evitaria, assim, diversos problemas associados à VC e aos princípios de $\mathrm{NdC}$, proporcionando uma abordagem diferente no tratamento de questões sobre $\mathrm{NdC}$ no currículo escolar de ciências ${ }^{13,14}$.

A título de exemplificação, podemos tomar brevemente uns poucos exemplos de como certos assuntos aparecem como 'tenets' e em nossa proposta. Por exemplo, o princípio "Leis e teorias desempenham diferentes papéis na ciência, então os estudantes deveriam notar que teorias não se tornam leis mesmo com evidências adicionais" passaria a ser explorado a partir de questões como: "O que caracteriza uma lei científica? O que caracteriza uma teoria científica? Leis e teorias, uma vez estabelecidas, são absolutas/definitivas? Existe algum tipo de hierarquia entre "lei" e "teoria"? Que diferenças existem entre o uso científico e o uso, na linguagem comum, dos termos "lei" e "teoria"?". O princípio "As ideias científicas são afetadas por seu meio social e histórico" seria explorado a partir de questões como: "Como o contexto histórico influencia a ciência? Quais as características da prática científica ao longo da história da humanidade? É possível dizer quando e onde começou o que chamamos hoje de ciência? É possível isolar a prática da ciência de outras práticas sociais? A ciência é uma prática social?". "O conhecimento científico, enquanto durável, tem um caráter tentativo" pode ser objeto de atenção de um conjunto mais amplo de temas (p. ex. "Natureza da explicação em ciência" e

\footnotetext{
${ }^{13}$ Certamente que outras perspectivas são possíveis, como, p.ex., a noção de 'campos teóricos estruturantes da filosofia da ciência' (ADÚRIZ-BRAVO, 2004; ADÚRIZ-BRAVO; IZQUIERDO-AYMERICH, 2009; ADÚRIZBRAVO; IZQUIERDO-AYMERICH; ESTANY, 2002) que, muito embora tenha sido desenvolvida no contexto de professores de ciência em formação e em serviço, poderia ser outro ponto de partida para se pensar desenhos curriculares.

${ }^{14}$ Em contexto semelhante (professores em treinamento), Taber (2008, ver Apêndice) apresenta um documento usado em Cambridge que oferece uma base para se pensar o planejamento de modelos curriculares para se ensinar aspectos de $\mathrm{NdC}$.
} 
"Poder e limitações do conhecimento científico"), com questões como: "O que é uma explicação científica? Como ela se diferencia de outras formas de explicação da realidade? Como as explicações científicas se relacionam com as evidências empíricas e os argumentos teóricos? O conhecimento científico é verdadeiro? Ele pode ser provado? Ele é definitivo ou pode sofrer alterações ao longo do tempo? Quais os seus limites de aplicabilidade? Qual o papel do ceticismo na ciência? É importante destacar o caráter investigativo que os temas devem assumir.

Certos temas e questões da Tabela não tem paralelo direto com os tenets (p. ex. o papel da matemática), enquanto outros realçam ainda mais as diferenças de abordagem (p. ex. "Ciência e outras formas de conhecimento" e "Diferenças entre áreas/disciplinas científicas"). Particularmente o último poderia ser explorado de modo cruzado ao longo de toda a Tabela, considerando como os demais temas e questões podem se aplicar a diferentes disciplinas científicas (p. ex. de que modo a física e a astronomia diferem em relação aos métodos e procedimentos que usam? Os mesmos métodos e procedimentos são usados em duas áreas distintas da Biologia - como botânica e genética?).

Novamente, aqui, cabe sinalizar que não se trata de uma mudança sutil ou aparente, mas de algo que pode ter um efeito significativo para guiar a inserção curricular do saber sobre a ciência. É uma abordagem que muda a forma e o conteúdo da perspectiva de trabalho com a temática NdC.

Um passo posterior para o desenvolvimento futuro dessa abordagem envolveria pensar em como articular temas e questões com conteúdos específicos. Esse passo representa um importante esforço na elaboração prática de currículos que incorporem a temática $\mathrm{NdC} \mathrm{e,} \mathrm{obvi-}$ amente, transcende o que é possível de ser discutido aqui. É importante dizer, no entanto, que um duplo movimento, de ir-e-vir, entre o conteúdo específico e o conteúdo metacientífico (representado pelos temas) a serem ensinados ajuda a pensar no desenvolvimento futuro dessa proposta e nas escolhas a serem feitas. Suponhamos, por exemplo, que um determinado assunto/conteúdo curricular (as leis de Newton ou a teoria da evolução, p. ex.) tenha sido escolhido. Podemos pensar: quais temas e questões (conteúdo metacientífico) são mais pertinentes de serem explorados/investigados com esses conteúdos? De que modo os temas e questões devem ser adaptados nesse caso em particular? Inversamente, dado um tema ou um conjunto limitado deles (p. ex. "correlação e causalidade" ou "métodos, procedimentos e processos da ciência"), poderíamos perguntar: quais assuntos/conteúdos (conteúdo científico) podem ser usados na exploração desses temas? Um ir-e-vir entre conteúdo científico específico e conteúdo metacientífico contribui para se pensar a inserção da temática $\mathrm{NdC}$ no currículo:

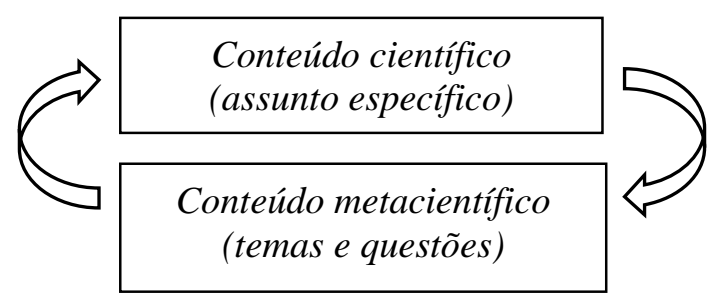


É importante sumarizar essa apresentação dizendo de que modo a abordagem proposta tenta dar conta de algumas críticas a VC e, nesse sentido, assume uma outra posição:

- $\quad$ Os temas e questões não se utilizam de conhecimento declarativo ou afirmações curtas e de domínio geral sobre a ciência. Não representam qualquer tipo de lista de afirmações que dizem o que a ciência é. Afasta-se, portanto, de boa parte das críticas feitas à VC a respeito da forma assumida por essa abordagem.

- De modo complementar ao item anterior, o conjunto de questões aponta para o caráter investigativo que o tratamento a temática $\mathrm{NdC}$ deve assumir na educação científica. Aproxima-se, assim, da perspectiva trazida, p. ex., por Clough (2007). Tal caráter investigativo tende a evitar - embora não haja uma garantia nesse sentido - uma série de problemas específicos que foram apontados em relação ao conteúdo dos tenets.

- Essa abordagem tem a vantagem de contemplar alguns temas e assuntos ausentes ou negligenciados pelas listas de tenets. P. ex., uma caracterização mais aprofundada dos processos da ciência e a ideia de modelagem, ou uma referência ao papel da matemática.

- Incorpora a perspectiva de um diálogo mais profícuo entre ciência e outras formas de conhecimento (esse tema surge diversas vezes nas Tabelas, sob os dois grandes eixos), bem como entre os diversos ramos da ciência (a importância de considerar as diferenças entre as disciplinas científicas está presente ao final de cada coluna na Tabela 1). Essa abordagem assume, portanto, um caráter mais aberto, plural e heterogêneo para o tratamento da temática $\mathrm{NdC}$, permitindo comparações entre disciplinas e áreas do conhecimento humano, tanto do ponto de vista histórico e social quanto epistemológico.

- $\quad$ Até certo grau, pode-se dizer que esta abordagem dialoga de modo mais frutífero com as propostas de Irzik e Nola $(2011,2014)$ - abordagem da "semelhança familiar" - e Matthews (2012) - abordagem das "características da ciência". Ao menos a abordagem por temas e questões é compatível com essas outras. Seria interessante comparar, de modo mais detalhado, nossa proposta com o que apresentam Irzik e Nola em seu trabalho mais recente (IRZIK; NOLA, 2014), uma vez que as divisões e categorias usadas por esses autores tem bastante sobreposição com a divisão e os temas que aparecem em nossa Tabela 1.

- Essa abordagem também pode ser considerada compatível com a defesa de Duschl e Grandy (2013) de uma visão de Construir e Refinar Práticas Científicas Baseadas em Modelos, no lugar de uma visão fundada em Princípios Heurísticos Baseados no Consenso. Tal compatibilidade, no entanto, dependeria dos desdobramentos futuros dos temas e questões a partir do uso específico de estratégias didáticas numa perspectiva de aprendizagem por investigação.

- De modo similar à observação precedente, acreditamos que os temas e questões são compatíveis com a abordagem sugerida por Allchin $(2011,2012)$ da "Whole Science". Novamente, aqui, tal compatibilidade dependeria dos desdobramentos futuros dos temas e questões com o uso específico de estudos de caso complexos e da ênfase na contextualização. Assim como a proposta da "Whole Science", e de modo complementar a ela, nossa abordagem pode ser considerada uma espécie de inventário que "pode funcionar como um 'checklist' curricular para rever a completude da temática $\mathrm{NdC}$ de um conjunto de vários estudos de caso (sejam 
históricos ou contemporâneos) e outras investigações de sala de aula" (ALLCHIN, 2011, p. 535, tradução nossa).

Por último, não é nossa intenção abordar aqui a questão do "como ensinar" ou estratégias didáticas em si mesmas. Esse campo é bastante amplo e diverso e foge ao escopo desse trabalho. A literatura tem evidenciado a relevância do uso da História da Ciência (via vinhetas, episódios, histórias curtas, estudos de caso etc.), de controvérsias (históricas e/ou atuais), da comparação da ciência com pseudociência, do ensino por investigação, artigos de jornais, argumentação, dentre outros, no ensino de conteúdos de NdC (p. ex.: ALLCHIN, 1997; HEERING, 2000; HÖTTECKE, 2000; DIMOPOULOS; KOULAIDIS, 2003; METZ et al., 2007; McCOMAS, 2008; TURGUT, 2011; FORATO; MARTINS; PIETROCOLA, 2012; EASTWOOD et al., 2012; BRAGA; GUERRA; REIS, 2012; SCHALK, 2012; CAPPS; CRAWFORD, 2013; KHISHFE, 2014). Algumas abordagens para o ensino-aprendizagem de conteúdos de natureza epistemológica podem ser encontradas em Ryder (2002).

No entanto, de uma maneira um pouco mais geral, acreditamos que alguns aspectos são anteriores às estratégias didáticas, mas a elas relacionados, e podem servir de guia para o estabelecimento das mesmas. É importante mencioná-los aqui porque eles aparecem na literatura especializada diretamente relacionados à questão do "o que ensinar" que tem sido o foco de atenção nesse trabalho. Referimo-nos àquilo que poderíamos denominar certas dimensões úteis para se pensar a inserção curricular de temas de NdC. Elas podem orientar a escolha de professores em sala de aula. Apresentamos três dessas dimensões, suscitados a partir de discussões presentes na literatura:

A) História de Ciência X "ciência atual/contemporânea": episódios históricos tem se mostrado fundamentais para o entendimento de questões que envolvem NdC (ALLCHIN, 1997; HEERING, 2000; HÖTTECKE, 2000; METZ et al., 2007; McCOMAS, 2008; RUDGE; HOWE, 2009; FORATO; MARTINS; PIETROCOLA, 2012; BRAGA; GUERRA; REIS, 2012, entre outros). Outros trabalhos evidenciam a relevância do uso de ciência atual/contemporânea para se discutir a temática NdC (DIMOPOULOS; KOULAIDIS, 2003; SADLER; CHAMBERS; ZEIDLER, 2004; WONG et al., 2008; MCCLUNE; JARMAN, 2010; EASTWOOD et al., 2012; KHISHFE, 2012, 2014, entre outros). Um olhar epistemológico da História da ciência, particularmente a respeito de controvérsias envolvendo cientistas, tem o potencial de ilustrar e contextualizar discussões sobre diversos aspectos relativos à temática $\mathrm{NdC}$. Com o aumento (em quantidade e qualidade) de materiais disponíveis a esse respeito, é sem dúvida uma perspectiva a ser considerada, embora professores continuem a ter uma formação deficiente em relação a um conhecimento satisfatório de História da ciência. Por outro lado, uma discussão sobre a ciência não pode prescindir de, em determinados momentos, tratar de temas atuais e da ciência contemporânea. Afinal, a NdC não se refere somente ao passado. Questões científicas atuais (como a recente busca pelo bóson de Higgs) costumam aparecer na mídia e despertar a curiosidade e o interesse dos estudantes, sendo uma boa oportunidade de tratar da temática NdC. Também temas controversos podem ser encontrados aqui, principalmente em questões sociocientíficas de interesse local ou global (p. ex. contaminação de um lago por produtos químicos ou o aquecimento global). Temas como os processos da ciência talvez sejam mais evidentes a partir dessa última abordagem. Porém, questões atuais tendem a ser 
bastante complexas e abertas, contrastando com situações históricas (até certo ponto "encerradas"), o que pode trazer outro tipo de dificuldades para os professores. De todo modo, parecenos importante sinalizar que a busca de um equilíbrio entre história de ciência e ciência "atual/contemporânea", ao longo do currículo, seria salutar (para uma discussão mais detalhada a respeito do uso tanto de episódios históricos como contemporâneos, ver CLOUGH, 2006 e ALLCHIN et al., 2014).

B) NdC contextual X NdC geral: essa é uma falsa dicotomia, na medida em que tais abordagens são complementares. No entanto, cabe apontar a necessária sinergia que deve existir entre ambas. De um lado, a discussão de aspectos da NdC é contexto-dependente, em dois sentidos: primeiro, porque o significado atribuído a determinadas afirmações só ganha sentido num determinado contexto (p. ex., o que significa coletar dados em física de partículas e em astronomia); segundo, porque são contextos específicos que ilustram e exemplificam afirmações de caráter geral sobre $\mathrm{NdC}$ (p. ex., que as observações feitas por Galileu dos satélites de Júpiter foram guiadas por pressupostos teóricos relativos ao copernicanismo e foram, portanto, "carregadas de teoria"). Por outro lado, a generalização de aspectos sobre NdC permite, justamente, que se vá criando uma imagem da ciência, ampliando a visão de que determinadas características são comuns a diversos contextos científicos (mas não a todos, necessariamente). O saber sobre a ciência também não pode se restringir a uma coleção de situações e afirmações desconexas, que só valem para casos específicos. Assim, novamente um equilíbrio parece ser necessário, de modo que a perspectiva contextual contribua para uma visão mais geral sobre a $\mathrm{NdC}$, ao mesmo tempo em que essa última seja percebida em diversos exemplos particulares. Esse equilíbrio deve ser buscado deliberadamente. Cabe destacar, porém, que nesse caso deve-se pressupor uma variação com o nível de escolaridade, uma vez que a abordagem contextual tende a ser a única viável em níveis mais elementares (em relação a este tópico, novamente há aproximação com o trabalho de Clough (2006), que propõe um extensivo e bem amparado ire-vir ao longo de um contínuo entre uma apresentação descontextualizada e uma altamente contextualizada, com vistas a promover uma profunda e robusta compreensão da NdC. A importância de uma abordagem contextualizada, principalmente quando pensamos sobre avaliações sobre NdC, é ressaltada por Allchin $(2011,2012)$ e Allchin et al. (2014)).

C) Epistemológico X sociológico: os dois grandes eixos em que situamos a perspectiva de um saber sobre a ciência complementam-se. Parece-nos importante, no entanto, sinalizar que o tratamento de alguns aspectos sociológicos (p. ex., questões éticas e políticas da pesquisa) tende a ganhar mais sentido em níveis escolares mais elevados. Assim, embora os diversos temas do eixo sociológico e do eixo epistemológico possam, com diferentes graus de profundidade, ser tratados nos diversos níveis de escolaridade, sugerimos que temas mais complexos do eixo sociológico sejam abordados mais adiante.

Os temas e questões deveriam ser explorados considerando-se apropriadamente essas dimensões. Dado um conteúdo específico e um conjunto de temas, por exemplo, podemos perguntar: como considerar essas três dimensões para desenhar uma estratégia de ensino? Esses conteúdos científicos e metacientíficos específicos são mais bem explorados usando-se episódios históricos? Ou com uma discussão sobre ciência atual/contemporânea no contexto de uma 
questão sociocientífica? De forma geral, é importante levar em conta a ideia de equilíbrio exposta acima: que escolhas curriculares devem ser feitas para contemplar tanto episódios históricos quanto contemporâneos? Que escolhas estimulariam o balanço entre $\mathrm{NdC}$ contextual e geral ao longo do currículo? E assim por diante.

Obviamente, essas "orientações" não esgotam o que poderia ser dito. Certamente muita pesquisa ainda trará contribuições ao entendimento de como abordar a temática $\mathrm{NdC}$ nos currículos escolares de ciências. O trabalho de Driver et al. (1996, p. 141), p. ex., evidenciou que um raciocínio baseado na percepção direta do fenômeno é mais comum em crianças menores do que em estudantes secundários, esses últimos utilizando mais um raciocínio baseado em relações. Apenas uma minoria de estudantes secundários mostraram-se mais capazes de raciocinar com modelos. Isso tem um impacto no planejamento de materiais curriculares, em geral, bem como do ensino dos processos e métodos da ciência, em particular. De modo semelhante, toda a metodologia do "aprendizado baseado em investigação" pode ter um papel importantíssimo para a temática $\mathrm{NdC}$, desde que não se acredite que a aprendizagem sobre a ciência possa se dar implicitamente ${ }^{15}$ (diversos trabalhos ressaltam o caráter explícito que deve ter qualquer abordagem sobre a NdC. Ver, p. ex.: LEDERMAN, 2007; McCOMAS, 2008; MCDONALD, 2010; BELL; MATKINS; GANSNEDER, 2011; KHISHFE, 2013, 2014).

A ideia de um currículo em espiral, em que temas relativos à $\mathrm{NdC}$ perpassem diversos níveis e disciplinas, e que ganhem generalidade e profundidade ao longo do tempo de escolaridade, é potencialmente atrativa. Pesquisas futuras podem lançar luzes nessa direção.

É preciso lembrar que a estruturação e o desenho de currículos é um processo mais amplo e complexo, que envolve - ou deveria envolver - uma série de atores sociais (educadores, políticos, membros da comunidade escolar, professores, pais e comunidades em geral, alunos) e não apenas educadores em ciência ${ }^{16}$. Assim, esses eixos, temas e questões podem servir de guias para escolhas curriculares que se construam a partir de contextos mais particulares/específicos, fornecidos, por exemplo: pelos conteúdos específicos e pelas disciplinas a serem ensinadas; pelo nível de ensino; por questões de interesse local, regional e nacional, entre outros. Em suma: trabalhando a partir de grandes eixos e temas, o detalhamento viria de modo mais contextualizado.

Certamente que o conhecimento construído na área de ensino de ciências a respeito desses eixos e temas gerais continua a ser a referência a ser consultada para esse detalhamento.

\footnotetext{
15 Para os partidários da VC, é importante não confundir NdC com "investigação" ("inquiry”), cuja história e tradição na área de educação científica é longa. Para eles, esta abordagem, além de não garantir uma aprendizagem adequada sobre $\mathrm{NdC}$, pode contribuir para propagar visões ingênuas da ciência, dependendo de como for realizada. Outros autores (p.ex. DUSCHL; GRANDY, 2013) argumentam exatamente o oposto, de que $\mathrm{NdC}$ e investigação devem ser agrupados. Não aprofundaremos essa discussão aqui.

${ }^{16}$ É claro que isso levanta um novo problema a ser enfrentado, na medida em que esses grupos, em geral, não estão familiarizados com a temática e, muitas vezes, manifestam ideias ingênuas sobre NdC. É relevante trazer aqui o argumento de Lakin e Wellington (1994) feito há vinte anos, de que o ensino da NdC parece ser contrário às "expectativas sobre a ciência e o ensino de ciências manifestas nas escolas, não somente por professores e alunos, mas também aquelas percebidas como sendo mantidas por pais e pela sociedade. Esse pode muito bem ser uma das grandes barreiras para introduzir a natureza da ciência no currículo de ciências" (LAKIN; WELLINGTON, 1994, p. 186, tradução nossa).
} 
Vemos aqui os campos da História, da Filosofia e da Sociologia da ciência alimentando a discussão em torno desses eixos, temas e questões. Sem um conhecimento mínimo razoável desses campos, o detalhamento desses temas, assim como as discussões sobre aquelas questões, pode não significar muita coisa e virar uma tarefa inócua. Pior do que isso, pode resultar numa lista de afirmações dogmáticas que misture diversas visões e não se torne operacional, sendo desprezada no futuro - e na prática - por professores de ciência nas escolas.

\section{Conclusão}

Mesmo com nomes diversos, uma alfabetização científica da população em geral continua a ser uma meta de todos aqueles preocupados com a educação em ciências. A menos que seja feita de modo dogmática e/ou limitada a um conhecimento do conteúdo da ciência - visto, erradamente, como um conjunto de fatos e afirmações sobre fenômenos - tal alfabetização não pode prescindir de um saber sobre a ciência.

Tal saber deve, necessariamente, representar uma superação de visões de senso comum acerca desse empreendimento humano, contextualizado histórica e socialmente, chamado ciência. A pesquisa em ensino de ciências avançou muito nessa direção e estamos, hoje em dia, em melhor posição para informar educadores, em geral, e elaborados de currículos, em particular, em relação a esse tipo de conteúdo metacientífico. Tal como é próprio da área de humanidades, a complexidade e riqueza de concepções permanecem sendo virtudes a serem valorizadas. Nesse sentido, a busca de uma visão consensual pode ser uma árdua tarefa.

A riqueza de ideias e perspectivas acerca da inserção curricular da $\mathrm{NdC}$ pode ser vislumbrada nos diversos caminhos pelos quais esse debate vem sendo conduzido na literatura da área de pesquisa em ensino de ciências, bem como na forma que essa discussão assume em documentos oficiais. A esse respeito, é interessante observar documentos recentes, como o Next Generation Science Standards (construído ao longo de muitos anos e com a participação de vários estados dos EUA) e a reforma do National Curriculum inglês a ser implementada pela primeira vez em 2014-2015 (respectivamente, NATIONAL RESEARCH COUNCIL, 2013, e DEPARTMENT FOR EDUCATION, 2013). Certamente que documentos de outros países e culturas trariam ainda maior riqueza a esse debate.

Se há, de fato, uma sabedoria partilhada acerca da $\mathrm{NdC}$, ela certamente pode assumir muitas formas. Nesse trabalho, procuramos apontar algumas das características e fragilidades da chamada VC, resgatando determinadas críticas a ela endereçadas. Sugerimos uma abordagem alternativa - baseada na ideia de temas no lugar de tenets - que busca superar a maioria dessas críticas, enquanto preserva a sabedoria partilhada construída pela pesquisa na área. Consideramos oportuno que a perspectiva da inserção da temática $\mathrm{NdC}$ nos currículos de ciência tenha um ponto de partida mais amplo e plural que, em certa medida, incorpora aquilo que vem sendo discutido na literatura. 
É importante e crucial reforçar que aquilo que foi apresentado aqui é uma proposta inicial. Trouxemos exemplos de temas e questões e não uma perspectiva que pretende ser exaustiva. Muitos outros passos são necessários para que essa abordagem possa ser implementada em contextos reais e avaliada. $\mathrm{O}$ desenvolvimento de pesquisas futuras que tomem essa abordagem como referência pode, sem dúvida, contribuir nessa direção.

A aproximação de grupos diversos, tais como educadores em ciência, historiadores, filósofos, sociólogos, cientistas, educadores em geral, professores e demais membros da comunidade escolar, tende a ser fundamental para a elaboração de currículos que façam sentido e respondam às demandas sociais. E mesmo bons currículos não trarão resultados significativos se não forem levados em conta outros polos dessa complexa relação: a formação de professores e as avaliações/exames:

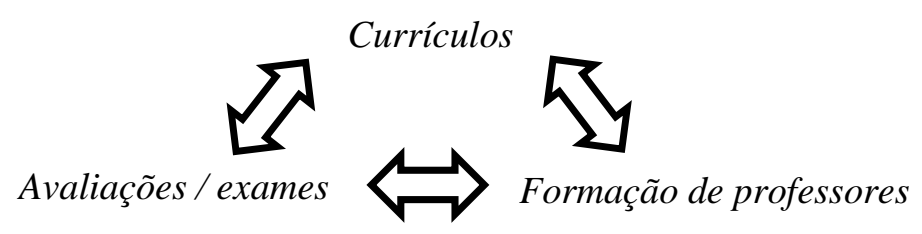

Nenhum currículo que contemple $\mathrm{NdC}$, seja desenhado a partir da visão consensual ou por meio de qualquer outra abordagem, vingará se os professores não estiverem suficientemente preparados e não considerarem que essa temática deva ser objeto de ensino, o que está estritamente relacionado à questão pragmática relativa àquilo que tem sido efetivamente avaliado. Embora nosso trabalho não tenha abordado os outros dois polos dessa tríade, é importante não perder de vista que eles estão conectados.

\section{Agradecimento}

O autor deseja agradecer à Coordenação de Aperfeiçoamento de Pessoal de Nível Superior (CAPES) pelo suporte financeiro ao projeto de pesquisa relacionado a essa publicação (processo número 4044-13-4).

\section{Referências}

ABD-EL-KHALICK, F. Examining the sources for our understandings about science: enduring conflations and critical issues in research on nature of science in science education. International Journal of Science Education, v. 34, n. 3, p. 353-374, 2012a.

ABD-EL-KHALICK, F. Nature of science in science education: toward a coherent framework for synergistic research and development. In: FRASER, B. J.; TOBIN, K; McROBBIE, C. (Eds.). Second international handbook of science education. The Netherlands: Springer, 2012b, p. 1041-1060. 
ADÚRIZ-BRAVO, A. Methodology and politics: a proposal to teach the structuring ideas of the philosophy of science through the pendulum. Science \& Education, v. 13, n. 7, p. 717-731, 2004.

ADÚRIZ-BRAVO, A.; IZQUIERDO-AYMERICH, M. A research-informed instructional unit to teach the Nature of Science to pre-service science teachers. Science \& Education, v. 18, n. 9, p. 1177-1192, 2009.

ADÚRIZ-BRAVO, A.; ROSALES, S. D. ¿Qué naturaleza de la ciencia hemos de saber los profesores que enseñamos ciencias? Uma questión actual de la investigación didáctica. In: ROSALES, S. F. D.; GATICA, M. R. Q. (Eds.). La enseñanza de las ciencias naturales en las primeras edades: su contribución a la promoción de competencias de pensamiento científico (Volumen 5). Barrancabermeja: Litodigital, 2011. Disponível em: <http://www7.uc.cl/sw_educ/educacion/grecia/plano/html/pdfs/biblioteca/LIBROS/LIBROMQSFIN.pdf> Acesso em: 22 Jan. 2015.

ADÚRIZ-BRAVO, A.; IZQUIERDO-AYMERICH, M.; ESTANY, A. Una propuesta para estructurar la ensenãnza de la filosofía de la ciencia para el profesorado de ciencias en formación. Ensenãnza de las Ciencias, v. 20, n. 3, p. 465-476, 2002.

ALLCHIN, D. Rekindling Phlogiston: from classroom case study to interdisciplinary relationships. Science \& Education, v. 6, n. 5, p. 473-509, 1997.

ALLCHIN, D. Should the Sociology of Science be rated X? Science Education, v. 88, n. 6, p. 934-946, 2004.

ALLCHIN, D. Evaluating knowledge of the nature of (Whole) Science. Science Education, v. 95, n. 3, p. 518-542, 2011.

ALLCHIN, D. Toward clarity on Whole Science and KNOWS. Science Education, v. 96, n. 4, p. 693-700, 2012.

ALLCHIN, D.; ANDERSEN, H. M.; NIELSEN, K. Complementary approaches to teaching Nature of Science: integrating student inquiry, historical cases, and contemporary cases in classroom practice. Science Education, v. 98, n. 3, p. 461-486, 2014.

ALTERS, B. J. Whose nature of science? Journal of Research in Science Teaching, v. 34, n. 1, p. 39-55, 1997.

BACHELARD, G. A Filosofia do Não - Filosofia do Novo Espírito Científico. Trad. Joaquim José Moura Ramos. 5. ed. Lisboa: Presença, 1991.

BACHELARD, G. A Formação do Espírito Científico. Trad. Estela dos Santos Abreu. Rio de Janeiro: Contraponto, 1996. 
BELL, R. L.; MATKINS, J. J.; GANSNEDER, B. M. Impacts of contextual and explicit instruction on preservice elementary teachers' understandings of the Nature of Science. Journal of Research in Science Teaching, v. 48, n. 4, p. 414-436, 2011.

BRAGA, M.; GUERRA, A.; REIS, J. C. The role of Historical-Philosophical controversies in teaching sciences: the debate between Biot and Ampère. Science \& Education, v. 21, n. 6, p. 921-934, 2012.

BRUSH, S. G. Should the History of Science be rated X? Science, New Series, v. 183, n. 4130, p. 1164-1172, Mar. 22, 1974.

CAPPS, D. K.; CRAWFORD, B. A. Inquiry-Based professional development: what does it take to support teachers in learning about inquiry and nature of science? International Journal of Science Education, v. 35, n. 12, p. 1947-1978, 2013.

CHEVALLARD, Y. La transposition didactique - Du savoir savant au savoir enseigné. 2 ed. Grenoble: La Pensée sauvage, 1985.

CLOUGH, M. P. Learners' responses to the demands of conceptual change: considerations for effective nature of science instruction. Science \& Education, v. 15, n. 5, p. 463-494, 2006.

CLOUGH, M. P. Teaching the nature of science to secondary and post-secondary students: questions rather than tenets. The Pantaneto Forum, 25, 2007. Disponível em: <http://www.pantaneto.co.uk/issue25/front25.htm>. Acesso em: 22 Jan. 2015.

DEPARTMENT FOR EDUCATION. The National Curriculum in England, 2013. Disponível em: <http://www.gov.uk/dfe/nationalcurriculum> Acesso em: 22 Jan. 2015.

DIMOPOULOS, K.; KOULAIDIS, V. Science and technology education for citizenship: the potential role of the press. Science Education, v. 87, n. 2, p. 241-256, 2003.

DRIVER, R. H.; LEACH, J.; MILLAR, R.; SCOTT, P. Young people's images of science. Buckingham: Open University Press, 1996.

DUSHL, R. A.; GRANDY, R. Two views about explicitly teaching Nature of Science. Science \& Education, v. 22, n. 9, p. 2109-2139, 2013.

EASTWOOD, J. L.; SADLER, T. D.; ZEIDLER, D. L.; LEWIS, A.; AMIRI, L.; APPLEBAUM, S. Contextualizing Nature of Science instruction in socioscientific issues. International Journal of Science Education, v. 34, n. 15, p. 2289-2315, 2012.

EFLIN, J. T.; GLENNAN, S.; REISCH, G. The Nature of Science: a perspective from the Philosophy of Science. Journal of Research in Science Teaching, v. 36, n. 1, p. 107-116, 1999. 
FERNÁNDEZ, I.; GIL-PÉREZ, D.; CARRASCOSA, J.; CACHAPUZ, A.; PRAIA, J. Visiones deformadas de la ciencia transmitidas por la enseñanza. Enseñanza de las Ciencias, v. 20, n. 3, p. 477-488, 2002.

FEYERABEND, P. Against method. 3. ed. London: Verso, 1993.

FORATO, T. C. M.; MARTINS, R. A.; PIETROCOLA, M. History and Nature of Science in high school: building up parameters to guide educational materials and strategies. Science $\&$ Education, v. 21, n. 5, p. 657-682, 2012.

GIL-PÉREZ, D.; MONTORO, I. F.; ALÍS, J. C.; CACHAPUZ, A.; PRAIA, J. Para uma imagen não deformada do trabalho científico. Ciência \& Educação, v. 7, n. 2, p. 125-153, 2001.

GOOD, R.; SHYMANSKY, J. Nature-of-Science literacy in benchmarks and standards: PostModern/Relativist or Modern/Realist? Science \& Education, v. 10, n. 1-2, p. 173-185, 2001.

HEERING, P. Getting shocks: teaching secondary school physics through history. Science \& Education, v. 9, n. 4, p. 363-373, 2000.

HIPKINS, R.; BARKER, M.; BOLSTAD, R. Teaching the 'nature of science': modest adaptations or radical reconceptions? International Journal of Science Education, v. 27, n. 2, p. 243-254, 2005.

HÖTTECKE, D. How and what can we learn from replicating historical experiments? A case study. Science \& Education, v. 9, n. 4, p. 343-362, 2000.

IRZIK, G.; NOLA, R. A Family Resemblance Approach to the Nature of Science for Science Education. Science \& Education, v. 20, n. 7-8, p. 591-607, 2011.

IRZIK, G.; NOLA, R. New directions for Nature of Science research. In: MATTHEWS, M. R. (Ed.). International Handbook of Research in History, Philosophy and Science Teaching. The Netherlands: Springer, 2014, p. 999-1021.

IZQUIERDO, M.; ADÚRIZ-BRAVO, A. Epistemological foundations of school science. Science \& Education, v. 12, n. 1, p. 27-43, 2003.

JENKINS, E. W. The 'nature of science' in the school curriculum: the great survivor. Journal of Curriculum Studies, v. 45, n. 2, p. 132-151, 2013.

KHISHFE, R. Nature of science and decision-making. International Journal of Science Education, v. 34, n. 1, p. 67-100, 2012.

KHISHFE, R. Transfer of Nature of Science understandings into similar contexts: promises and possibilities of an explicit reflective approach. International Journal of Science Education, v. 35, n. 17, p. 2928-2953, 2013. 
KHISHFE, R. Explicit Nature of Science and argumentation instruction in the context of Socioscientific Issues: An effect on student learning and transfer. International Journal of Science Education, v. 36, n. 6, p. 974-1016, 2014.

KRAGH, H. Social constructivism, the gospel of science, and the teaching of physics. Science \& Education, v. 7, n. 3, p. 231-243, 1998.

KROGH, L. B.; NIELSEN, K. Introduction: How Science Works - and how to teach it. Science \& Education, v. 22, n. 9, p. 2055-2065, 2013.

LAKIN, S.; WELLINGTON, J. Who will teach the nature of science?: Teachers' views of science and their implications for science education. International Journal of Science Education, v. 16, n. 2, p. 175-190, 1994.

LEDERMAN, N. G. Student's and teacher's conceptions of the nature of science: a review of the research. Journal of Research in Science Teaching, v. 29, n. 4, p. 331-359, 1992.

LEDERMAN, N. G. Nature of science: past, present and future. In: ABELL, S. K.; LEDERMAN, N.G. (Eds.). Handbook of research on science education. Mahwah, NJ: Lawrence Erlbaum Associates, 2007, p. 831-879.

LEDERMAN, N. G.; BARTOS, S. A.; LEDERMAN, J. S. The development, use, and interpretation of Nature of Science assessments. In: MATTHEWS, M. R. (Ed.). International Handbook of Research in History, Philosophy and Science Teaching. The Netherlands: Springer, 2014, p. 971-997.

MARTINS, A. F. P. Knowledge about science in science education research from the perspective of Ludwik Fleck's epistemology. Research in Science Education, 2015, DOI: 10.1007/s11165-015-9469-7.

MARTINS, A. F. P.; RYDER, J. Nature of Science in science education: a proposal based on 'themes'. In: GIREP-MPTL INTERNATIONAL CONFERENCE ON TEACHING/ LEARNING PHYSICS, 2015, Palermo, Italy, Università di Palermo. Proceedings...

MATTHEWS, M. R. Science Teaching: the role of History and Philosophy of Science. New York: Routledge, 1994a.

MATTHEWS, M. R. Vino viejo en botellas nuevas: un problema con la epistemología constructivista. Enseñanza de las Ciencias, v. 12, n. 1, p. 79-88, 1994b.

MATTHEWS, M. R. Editorial. Science \& Education, v. 6, n. 4, p. 323-329, 1997.

MATTHEWS, M. R. Foreword and introduction. In: McCOMAS, W. F. (Ed.). The Nature of Science in Science Education: rationales and strategies. The Netherlands: Kluwer, 1998, p. xixxi. 
MATTHEWS, M. R. Changing the focus: from nature of science to features of science. In: KHINE, M. S. (Ed.). Advances in nature of science research. Dordrecht: Springer, 2012, p. $3-26$.

MCCLUNE, B.; JARMAN, R. Critical reading of science-based news reports: Establishing a knowledge, skills and attitudes framework. International Journal of Science Education, v. 32, n. 6, p. 727-752, 2010.

McCOMAS, W. F. Seeking historical examples to illustrate key aspects of the nature of science. Science \& Education, v. 17, n. 2-3, p. 249-263, 2008.

McCOMAS, W. F.; OLSON, J. K. The Nature of Science in international science educational standards documents. In: McCOMAS, W. F. (Ed.). The Nature of Science in Science Education: rationales and strategies. The Netherlands: Kluwer, 1998. p. 41-52.

McCOMAS, W. F.; ALMAZROA, H.; CLOUGH, M. The Nature of Science in Science Education: an introduction. Science \& Education, v. 7, n. 6, p. 11-532, 1998a.

McCOMAS, W. F.; CLOUGH, M.; ALMAZROA, H. The role and character of the Nature of Science in Science Education. In: McCOMAS, W. F. (Ed.). The Nature of Science in Science Education: rationales and strategies. The Netherlands: Kluwer, 1998b, p. 3-39.

McDONALD, C. V. The influence of explicit Nature of Science and argumentation instruction on preservice primary teachers' views of Nature of Science. Journal of Research in Science Teaching, v. 47, n. 9, p. 1137-1164, 2010.

METZ, D.; KLASSEN, S.; MCMILLAN, B.; CLOUGH, M.; OLSON, J. Building a foundation for the use of historical narratives. Science \& Education, v. 16, n. 3-5, p. 313-334, 2007.

NATIONAL RESEARCH COUNCIL. Next Generation Science Standards: For States, By States. Washington, D.C.: The National Academies Press, 2013.

OGBORN, J. Constructivist metaphors of learning science. Science \& Education, v. 6, n. 1-2, p. 21-133, 1997.

OSBORNE, J. Beyond Constructivism. Science Education, v. 80, n. 1, p. 53-82, 1996.

OSBORNE, J.; COLLINS, S.; RATCLIFFE, M.; MILLAR, R.; DUSCHL, R. What "Ideasabout-Science" should be taught in school science? A Delphi study of the expert community. Journal of Research in Science Teaching, v. 40, n. 7, p. 692-720, 2003.

PLANCK, M. K. E. L. Scientific autobiography and other papers. London: Williams \& Norgate, 1950. 
RUDGE, D. W.; HOWE, E. M. An explicit and reflective approach to the use of history to promote understanding of the Nature of Science. Science \& Education, v. 18, n. 5, p. 561-580, 2009.

RUDOLPH, J. L. Reconsidering the 'nature of science' as a curriculum component. Journal of Curriculum Studies, v. 32, n. 3, p. 403-419, 2000.

RYDER, J. Identifying science understanding for functional scientific literacy. Studies in Science Education, v. 36, n. 1, p. 1-44, 2001.

RYDER, J. School science education for citizenship: strategies for teaching about the epistemology of science. Journal of Curriculum Studies, v. 34, n. 6, p. 637-658, 2002.

SADLER, T. D.; CHAMBERS, F. W.; ZEIDLER, D. L. Student conceptualizations of the nature of science in response to a socio-scientific issue. International Journal of Science Education, v. 26, n. 4, p. 387-409, 2004.

SCHALK, K. A. A Socioscientific Curriculum facilitating the development of distal and proximal NOS conceptualizations. International Journal of Science Education, v. 34, n. 1, p. 1$24,2012$.

TABER, K. S. Towards a curricular model of the Nature of Science. Science \& Education, v. 17, n. 2-3, p. 179-218, 2008.

TURGUT, H. The context of demarcation in Nature of Science teaching: the case of Astrology. Science \& Education, v. 20, n. 5-6, p. 491-515, 2011.

VAN DIJK, E. M. Portraying real science in science communication. Science Education, v. 95, n. 6, p. 1086-1100, 2011.

WONG, S. L.; HODSON, D.; KWAN, J.; YUNG, B. H. Y. Turning crisis into opportunity: Enhancing student-teachers' understanding of nature of science and scientific inquiry through a case study of the scientific research in severe acute respiratory syndrome. International Journal of Science Education, v. 30, n. 11, p. 1417-1439, 2008. 